\title{
Biochemical characterization of three new a-olefin-producing P450 fatty acid decarboxylases with a halophilic property
}

Yuanyuan Jiang ${ }^{1,2}$, Zhong $\mathrm{Li}^{1,2}$, Cong Wang ${ }^{1}$, Yongjin J. Zhou ${ }^{3}$, Huifang $\mathrm{Xu}^{1 *}$ and Shengying $\mathrm{Li}^{1,4,5^{*}}$

\begin{abstract}
Background: The CYP152 family member OleT JE from Jeotgalicoccus sp. ATCC 8456 has been well-known to catalyze the unusual one-step decarboxylation of free fatty acids towards the formation of terminal alkenes. Efforts to tune up its decarboxylation activity for better production of biological alkenes have been extensively explored via approaches such as site-directed mutagenesis and electron source engineering, but with limited success. To gain more insights into the decarboxylation mechanism and reaction bifurcation (decarboxylation versus hydroxylation), we turned to an alternative approach to explore the natural CYP152 resources for a better variety of enzyme candidates.

Results: We biochemically characterized three new P450 fatty acid decarboxylases including $\mathrm{OleT}_{\mathrm{H}} \mathrm{OleT}_{\mathrm{SQ}}$ and $\mathrm{OleT}_{S A}$, with respect to their substrate specificity, steady-state kinetics, and salt effects. These enzymes all act as an OleT $\mathrm{JE}_{\mathrm{E}}$-like fatty acid decarboxylase being able to decarboxylate a range of straight-chain saturated fatty acids $\left(\mathrm{C}_{8}-\mathrm{C}_{20}\right)$ to various degrees. Site-directed mutagenesis analysis to the lower activity P450 enzyme OleT $\mathrm{SA}_{\mathrm{A}}$ revealed a number of key amino acid residues within the substrate-binding pocket (T47F, 1177L, V319A and L405I) that are important for delicate substrate positioning of different chain-length fatty acids and thus the decarboxylation versus hydroxylation chemoselectivity, in particular for the mid-chain fatty acids $\left(C_{8}-C_{12}\right)$. In addition, the three new decarboxylases exhibited optimal catalytic activity and stability at a salt concentration of $0.5 \mathrm{M}$, and were thus classified as moderate halophilic enzymes.
\end{abstract}

Conclusion: The P450 fatty acid decarboxylases $\mathrm{OleT}_{\mathrm{JE},} \mathrm{OleT}_{\mathrm{HH}^{\prime}} \mathrm{OleT}_{\mathrm{SQ}}$ and $\mathrm{OleT}_{\mathrm{SA}}$ belong to a novel group of moderate halophilic P450 enzymes. OleT $T_{J}$ from Jeotgalicoccus halophilus shows the decarboxylation activity, kinetic parameters, as well as salt tolerance and stability that are comparable to Ole $\mathrm{T}_{\mathrm{JE}}$. Site-directed mutagenesis of several key amino acid residues near substrate-binding pocket provides important guidance for further engineering of these P450 fatty acid decarboxylases that hold promising application potential for production of a-olefin biohydrocarbons.

Keywords: P450 fatty acid decarboxylase, Fatty acid, Alkene, Biofuel, Halophilic enzymes

\footnotetext{
*Correspondence: xu_hf@qibebt.ac.cn; lishengying@sdu.edu.cn

'1 Shandong Provincial Key Laboratory of Synthetic Biology, CAS Key

Laboratory of Biofuels, Qingdao Institute of Bioenergy and Bioprocess

Technology, Chinese Academy of Sciences, No. 189 Songling Road,

Qingdao 266101, Shandong, China

Full list of author information is available at the end of the article
}

(c) The Author(s) 2019. This article is distributed under the terms of the Creative Commons Attribution 4.0 International License (http://creativecommons.org/licenses/by/4.0/), which permits unrestricted use, distribution, and reproduction in any medium, provided you give appropriate credit to the original author(s) and the source, provide a link to the Creative Commons license, and indicate if changes were made. The Creative Commons Public Domain Dedication waiver (http://creativecommons.org/ publicdomain/zero/1.0/) applies to the data made available in this article, unless otherwise stated. 


\section{Background}

Development of renewable, sustainable, and cost-effective biofuels has been driven by the shortage of fossil fuels, serious environmental problems, and ever-changing geopolitical factors [1, 2]. Among different types of biofuels, biohydrocarbons have attracted much attention as an ideal alternative to petroleum-based fuels due to their high energy content, low hygroscopicity, and compatibility with existing engine and distribution systems [3-7].

Cytochrome P450 (CYP) enzymes are a superfamily of proteins with a thiolate-heme prosthetic group, which are renowned for their versatile catalytic activities and exceptional capability to accept a vast variety of substrates [810]. According to the catalytic properties, P450 enzymes can be classified into monooxygenases, peroxidases, and peroxygenases [10]. The biofuel-related P450 fatty acid decarboxylases (FADCs), such as OleT $_{\text {IE }}$ from Jeotgalicoccus sp. ATCC 8456 [11] and CYP-Sm46 from Staphylococcus massiliensis S46 [12], belong to the CYP152 peroxygenase family. This family of $\mathrm{P} 450$ enzymes utilizes $\mathrm{H}_{2} \mathrm{O}_{2}$, instead of $\mathrm{O}_{2}$ which is employed by most of $\mathrm{P} 450$ monooxygenases, as the oxidant to support the unique oxidative decarboxylation reactions (Fig. 1) that convert the $C_{n}(n=4-22)$ chain length free fatty acids (FFAs) into $C_{n-1}$ chain length 1-alkenes (i.e., $\alpha$-olefins) [13, 14]. Since $\alpha$-olefins are both excellent biofuel molecules and useful precursors of lubricants, detergents and other chemicals $[15,16]$, P450 FADCs hold promising application potential for production of biological $\alpha$-olefins.

A majority of CYP152 peroxygenases catalyze FFA hydroxylation and decarboxylation reactions simultaneously. According to the main catalytic reaction types, this family of P450 enzymes can be classified into $\mathrm{P} 450_{\mathrm{BS} \beta}$-like FFA hydroxylases (i.e., those with FFA hydroxylation as major chemistry, such as $\mathrm{P} 450_{\mathrm{BS} \beta}$ mainly produces similar amounts of $\alpha$ - and $\beta$-hydroxyl fatty

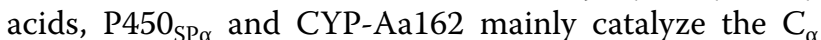
hydroxylation of FFAs, CYP-MP introduces the hydroxyl group at various carbon positions, and $\mathrm{OleT}_{\mathrm{MC}}$ prefers to hydroxylate the long-chain fatty acids) and Ole $\mathrm{T}_{\mathrm{IE}}$-like FFA decarboxylases (i.e., those preferentially catalyze
FFA decarboxylation reaction, like $\mathrm{OleT}_{\mathrm{IE}}$ and CYPSm46 29 ) [11, 12, 14, 17-19]. To understand the unusual decarboxylation mechanism for activity and selectivity optimization, a growing number of studies on the prototypic P450 FADC OleT ${ }_{\mathrm{IE}}$ have been carried out [20-29]. For example, Munro et al. resolved the crystal structures of wild-type $\mathrm{OleT}_{\mathrm{JE}}$ [28] and a number of mutants such as $\mathrm{R} 245 \mathrm{~L} / \mathrm{E}, \mathrm{F} 79 \mathrm{~A} / \mathrm{Y} / \mathrm{W}$ and $\mathrm{H} 85 \mathrm{Q}$ [30], revealing the important roles of Arg245, His85, and Phe79 in both catalytic activity and decarboxylation/hydroxylation bifurcation, as well as a group of active site residues responsible for productive fatty acid substrate binding. Furthermore, systematic mutagenesis analyses of a select group of active site residues including Arg245, His85 and Ile170 suggested the accurate substrate positioning is essential for decarboxylation activity $[19,27,30,31]$.

Interestingly, $\mathrm{OleT}_{\mathrm{IE}}$, the first identified P450 FADC remains the best biocatalyst for $\alpha$-olefin production in terms of both catalytic efficiency and chemoselectivity (i.e., decarboxylation versus hydroxylation) when compared to other biochemically characterized P450 FADCs including $\mathrm{P}^{4} 0_{\mathrm{BS} \beta}, \mathrm{CYP}-\mathrm{MP}$, Ole $\mathrm{T}_{\mathrm{MC}}$, CYP-Aa162, and CYP-Sm46 29 [12, 19, 32]. Of note, some approaches such as redox partner engineering [31] and development of photocatalytic systems [33, 34] were also unsuccessful to improve the decarboxylation activity of $\mathrm{OleT}_{\mathrm{IE}}$. Thus, it is highly expected to discover or engineer a novel CYP152 biocatalyst that can convert FFAs to 1-alkenes more efficiently and selectively.

In this work, we in vitro characterized three novel CYP152 FADCs including OleT $_{\mathrm{JH}}$ from Jeotgalicoccus halophilus (CYP152L1_ortholog, GenBank accession number: WP_092595307), OleT $\mathrm{SQ}_{\mathrm{SQ}}$ from Salinicoccus qingdaonensis (CYP152L8, WP_092983663), and $\mathrm{OleT}_{\mathrm{SA}}$ from Staphylococcus aureus (CYP152L7, WP_049319149). We determined the substrate preference, kinetic parameters and salt tolerance of these enzymes for the first time. Moreover, site-directed mutagenesis on $\mathrm{OleT}_{\mathrm{SA}}$, the OleT with relatively lower activity, was performed in order to further understand the function of active site residues in the catalytic activity and chemoselectivity of P450 FADCs.

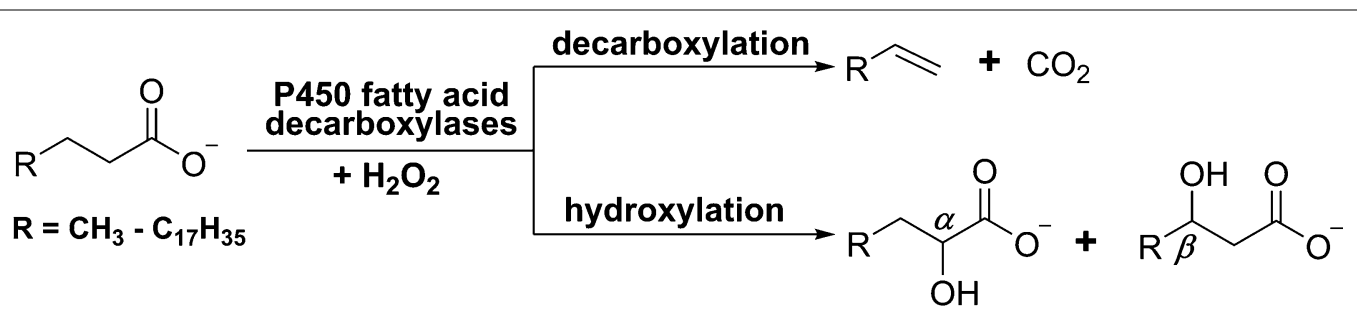

Fig. 1 Decarboxylation and hydroxylation reactions catalyzed by P450 fatty acid decarboxylases 


\section{Results}

Genome mining of OleT $_{\mathrm{JE}^{-}}$-like P450 fatty acid decarboxylases

The number of biochemically characterized P450 FADCs is far less than that of existing CYP152 sequences with potential FFA oxidation activities in GenBank. To explore more P450 FADCs that may possess greater decarboxylation activity and/or selectivity, we built a phylogenetic tree (Fig. 2) based on the protein sequences of the two known P450 FADCs OleT JE (CYP152L1) and CYPSm46 29 (CYP152L2), and their homologous sequences with a sequence identity higher than $60 \%$. Interestingly, these sequences mostly originate from the genera of Jeotgalicoccus, Staphylococcus, and Salinicoccus, which are well-known microorganisms associated with halophilicity or salt tolerance [35-38]. This finding suggests a possibility of identifying more 1-alkene producers and FADCs with higher decarboxylation activities from these groups of microorganisms.

Next, based on the conserved residues that are believed to be essential for the decarboxylation activity, including Phe79, His85, Ile170 and Arg245 (OleT $_{\mathrm{JE}}$ numbering, Additional file 1: Figure S1), we from each major branch selected $\mathrm{OleT}_{\mathrm{JH}}$ from Jeotgalicoccus halophilus

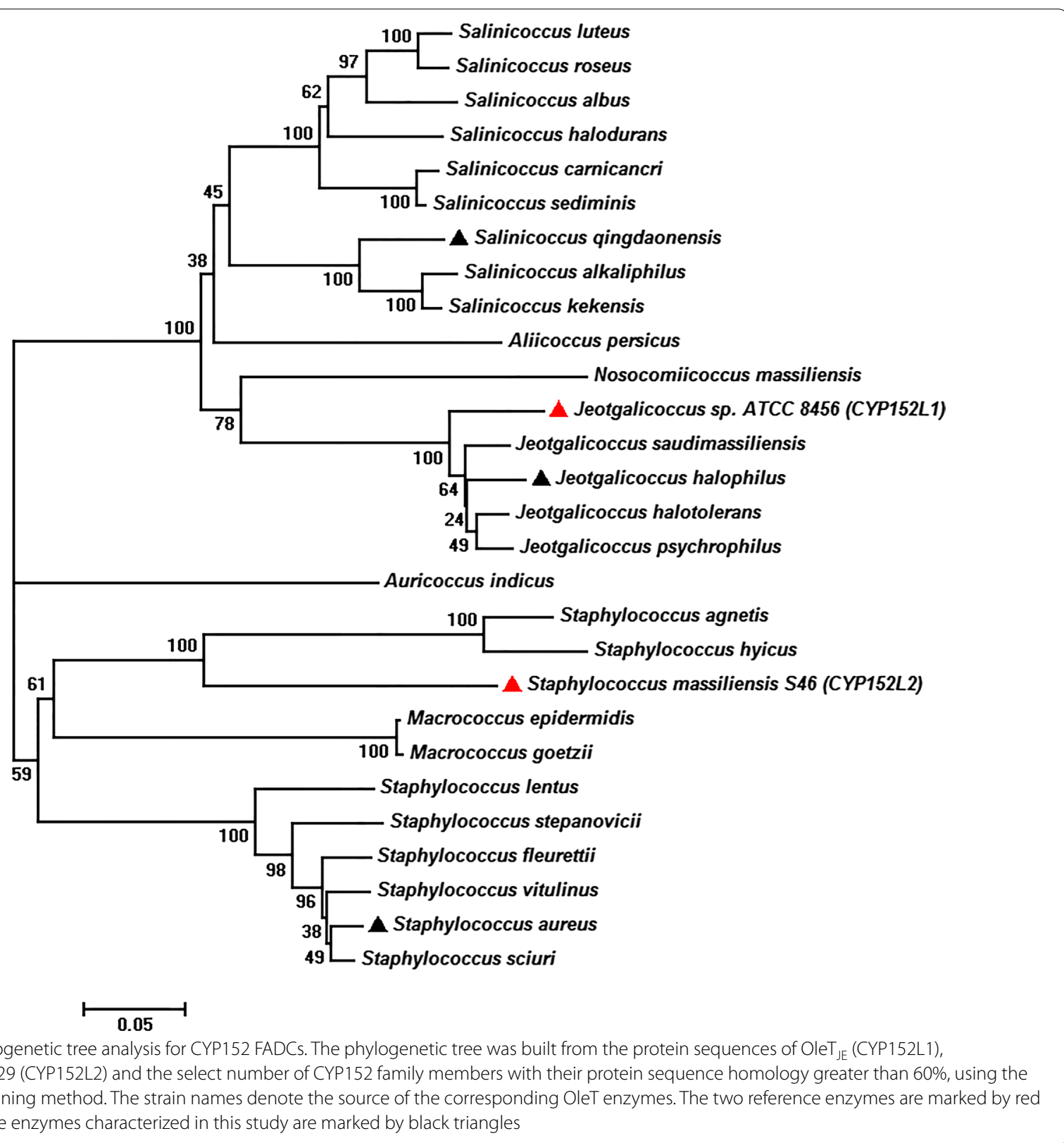


(CYP152L1_ortholog, GenBank accession number: WP_092595307), $\mathrm{OleT}_{\mathrm{SQ}}$ from Salinicoccus qingdaonensis (CYP152L8, WP_092983663), and $\mathrm{OleT}_{\mathrm{SA}}$ from Staphylococcus aureus (CYP152L7, WP_049319149) for our following biochemical characterization. According to the protein sequence alignment (Additional file 1: Table $\mathrm{S} 1$ and Additional file 2), $\mathrm{OleT}_{\mathrm{JH}}, \mathrm{OleT}_{\mathrm{SQ}}$, and $\mathrm{OleT}_{\mathrm{SA}}$ show $93 \%(62 \%), 76 \%(63 \%)$, and $69 \%(64 \%)$ amino acid sequence identity to $\mathrm{OleT}_{\mathrm{JE}}(\mathrm{CYP}-\mathrm{Sm} 46 \Delta 29)$, respectively.

\section{Substrate specificity and chemoselectivity}

The codon-optimized genes that encode $\mathrm{OleT}_{\mathrm{IH}}, \mathrm{OleT}_{\mathrm{SQ}}$, and $\mathrm{OleT}_{\mathrm{SA}}$ were individually expressed in Escherichia coli BL21(DE3). The resultant $\mathrm{N}$-terminal $\mathrm{His}_{6}$-tagged recombinant proteins were purified to homogeneity using nickel affinity chromatography (Additional file 1: Figure S2). As expected, the three enzymes showed characteristic CO-bound reduced difference spectra (Additional file 1: Figure S3), indicative of their functional expression.

Using purified OleT enzymes, we determined their activities towards a range of straight-chain saturated fatty acids $\left(\mathrm{C}_{8}-\mathrm{C}_{20}\right)$ with $\mathrm{H}_{2} \mathrm{O}_{2}$ as cofactor. As results, all the four enzymes exhibited similar substrate preference profiles with decanoic acid $\left(\mathrm{C}_{10}\right)$ or lauric acid $\left(\mathrm{C}_{12}\right)$ as their optimal substrate (Fig. 3). The lauric acid conversion ratios were $93.8 \pm 6.1 \%, 98.6 \pm 0.6 \%, 99.1 \pm 0.2 \%$, and $86.2 \pm 1.9 \%$ for $\mathrm{OleT}_{\mathrm{JE}}, \mathrm{OleT}_{\mathrm{JH}}, \mathrm{OleT}_{\mathrm{SQ}}$, and $\mathrm{OleT}_{\mathrm{SA}}$, respectively. With respect to the productivity of 1-alkenes, lauric acid was the best substrate unanimously. Of note, $\mathrm{OleT}_{\mathrm{JE}}, \mathrm{OleT}_{\mathrm{JH}}$, and $\mathrm{OleT}_{\mathrm{SQ}}$ exhibited higher decarboxylation (DC) activities than hydroxylation (HD) activities with the DC/HD values up to 38.3 when $\mathrm{C}_{10}-\mathrm{C}_{14}$ FFAs were used as substrates. However, $\mathrm{OleT}_{\mathrm{SA}}$ only showed moderately higher alkene production from its optimal substrates lauric acid $(\mathrm{DC} / \mathrm{HD}=2.6)$ and
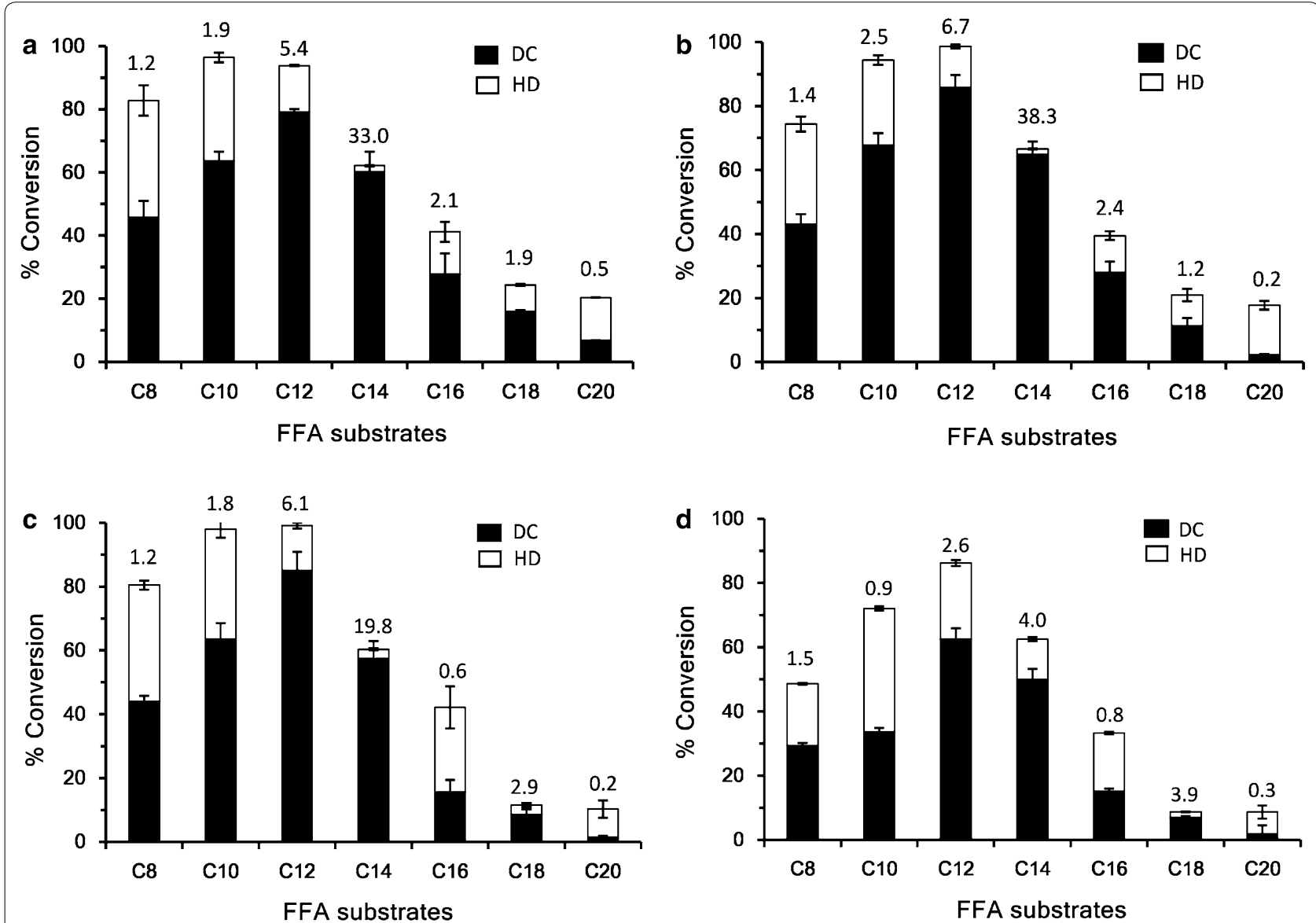

Fig. 3 Substrate preference and product distribution profiles of $\operatorname{Ole}_{\mathrm{JE}}(\mathbf{a}), \mathrm{Ole}_{\mathrm{JH}}(\mathbf{b}), \mathrm{Ole}_{\mathrm{SQ}}(\mathbf{c})$, and $\mathrm{OleT}_{\mathrm{SA}}(\mathbf{d})$. The hydroxylation (HD) activity was calculated by subtracting the percentage of 1-alkene production from the total substrate conversion ratio. Results are shown as mean \pm SD of two parallel experiments. In a standard assay, $1 \mu \mathrm{M}$ of each OleT enzyme, $200 \mu \mathrm{M}$ fatty acid substrate $\left(\mathrm{C}_{8}-\mathrm{C}_{20} \mathrm{FFAs}\right)$, and $220 \mu \mathrm{M} \mathrm{H} \mathrm{H}_{2} \mathrm{O}_{2}$ were co-incubated in a $200-\mu \mathrm{L}$ reaction system. The reactions were carried out at $30^{\circ} \mathrm{C}$ for $2 \mathrm{~h}$ 
myristic acid $(\mathrm{DC} / \mathrm{HD}=4.0)$. By contrast, such chemoselectivity was entirely reversed when the long-chain FFA arachidic acid $\left(\mathrm{C}_{20}\right)$ was the substrate, suggesting that substrates with different carbon-chain length could adopt distinct substrate-binding modes, thereby impacting the preference for decarboxylation or hydroxylation.

Subsequently, we elected to perform more detailed analyses of the myristic acid conversions catalyzed by all four OleT enzymes for two reasons: (1) myristic acid gave the highest $\mathrm{DC} / \mathrm{HD}$ values among the tested FFAs, thus being the optimal decarboxylation substrate; (2) the commercial availability of $\alpha$ - and $\beta$-hydroxy myristic acid would enable quantification of the hydroxylation products. As expected, $\operatorname{OleT}_{\mathrm{JE}}, \mathrm{OleT}_{\mathrm{H}}, \mathrm{OleT}_{\mathrm{SQ}}$, and $\mathrm{OleT}_{\mathrm{SA}}$ all produced 1-tridecene as the dominant product. As for hydroxylation products, $\beta-\mathrm{OH}$-myristic acid was the major hydroxylation product $(6.8-15.4 \%$ of the total products), $\alpha-\mathrm{OH}$-myristic acid only accounted for less than $1 \%$ of the total products, and no $\gamma^{-}, \delta_{-}^{-}$, or $\varepsilon$-hydroxylated products were detected (Table 1). Taken together, $\operatorname{OleT}_{\mathrm{JH}}, \mathrm{OleT}_{\mathrm{SQ}}$, and $\mathrm{OleT}_{\mathrm{SA}}$ are three new OleT $_{\text {IE }}$-like FADCs, which can sometimes outperform the decarboxylation activity of $\mathrm{OleT}_{\mathrm{JE}}$, depending on the FFA substrates to be decarboxylated.

To further quantitatively evaluate the catalytic efficiencies of $\mathrm{OleT}_{\mathrm{JH}}, \mathrm{OleT}_{\mathrm{SQ}}$, and $\mathrm{OleT}_{\mathrm{SA}}$, we determined their steady-state kinetic parameters (Table 2) towards the optimal substrate lauric acid $\left(\mathrm{C}_{12}\right)$ with $\mathrm{OleT}_{\mathrm{IE}}$ as a control (Additional file 1: Figure S4). By measuring the initial substrate consumption rates with gas chromatography, we found that the kinetic parameters of $\mathrm{OleT}_{\mathrm{JH}}$ were mostly similar to those of the control FADC OleT $\mathrm{JE}_{\mathrm{E}}$ with a slightly higher catalytic activity $\left(k_{\text {cat }}\right)$. In comparison, $\mathrm{OleT}_{\mathrm{SQ}}$ and $\mathrm{OleT}_{\mathrm{SA}}$ displayed relatively lower catalytic efficiency $\left(k_{\text {cat }} / K_{m}\right)$ due to their attenuated $k_{\text {cat }}$ values, albeit a slightly higher lauric acid substrate-binding affinity reflected by their lower $K_{m}$. This may seem inconsistent with the previous results that $\mathrm{OleT}_{\mathrm{SQ}}$ showed higher conversion rate $(99.1 \pm 0.2 \%)$ towards lauric acid than $\mathrm{OleT}_{\mathrm{IE}}(93.8 \pm 6.1 \%)$. We reason this contradiction might

Table 1 GC-MS analysis of substrate conversions and product distribution profiles of the four FADCs using myristic acid $\left(C_{14}\right)$ as substrate

\begin{tabular}{|c|c|c|c|c|}
\hline \multirow[t]{2}{*}{ Enzymes } & \multirow[t]{2}{*}{ Conversion (\%) } & \multicolumn{3}{|c|}{ Product distribution (\%) } \\
\hline & & 1-Tridecene & $\mathrm{a}-\mathrm{OH}-\mathrm{C}_{14}$ & $\beta-\mathrm{OH}-\mathrm{C}_{14}$ \\
\hline $\mathrm{OleT}_{\mathrm{JE}}$ & $67.1 \pm 2.5$ & $91.7 \pm 0.5$ & $0.6 \pm 0.1$ & $7.8 \pm 0.4$ \\
\hline $\mathrm{OleT}_{J H}$ & $69.2 \pm 4.6$ & $92.9 \pm 1.3$ & $0.3 \pm 0.1$ & $6.8 \pm 1.4$ \\
\hline $\mathrm{OleT}_{S Q}$ & $62.6 \pm 1.7$ & $91.1 \pm 0.5$ & $0.2 \pm 0.1$ & $8.8 \pm 0.5$ \\
\hline $\mathrm{OleT}_{S A}$ & $60.7 \pm 10.3$ & $84.0 \pm 6.5$ & $0.6 \pm 0.3$ & $15.4 \pm 6.2$ \\
\hline
\end{tabular}

Table 2 Steady-state kinetic parameters and reaction turnover numbers (TONs) of the four OleT enzymes

\begin{tabular}{|c|c|c|c|c|c|}
\hline \multirow[t]{2}{*}{ Enzymes } & \multicolumn{3}{|c|}{ Kinetic parameters } & \multirow[t]{2}{*}{ TON $^{\mathrm{a}}$} & \multirow[t]{2}{*}{ TON $^{\mathrm{b}}$} \\
\hline & $k_{\text {cat }}\left(\min ^{-1}\right)$ & $K_{m}(\mu \mathrm{M})$ & $\begin{array}{l}k_{\mathrm{cat}} / K_{m} \\
\left(\mathrm{~min}^{-1}\right. \\
\left.\mu \mathrm{M}^{-1}\right)\end{array}$ & & \\
\hline $\mathrm{OleT}_{\mathrm{JE}}$ & $860 \pm 28$ & $41 \pm 4$ & 21 & 95 & 185 \\
\hline OleT $_{J H}$ & $910 \pm 113$ & $46 \pm 15$ & 20 & 100 & 180 \\
\hline $\mathrm{OleT}_{\mathrm{SQ}}$ & $570 \pm 55$ & $35 \pm 10$ & 16 & 53 & 144 \\
\hline $\mathrm{OleT}_{S A}$ & $600 \pm 13$ & $37 \pm 7$ & 16 & 38 & 94 \\
\hline
\end{tabular}

a $\mathrm{H}_{2} \mathrm{O}_{2}$-batch: $1 \mathrm{mM} \mathrm{H}_{2} \mathrm{O}_{2}, 1 \mathrm{mM}$ substrate (lauric acid), $1 \mu \mathrm{M}$ purified OleT, $30^{\circ} \mathrm{C}$, $12 \mathrm{~h}$

${ }^{b} \mathrm{H}_{2} \mathrm{O}_{2}$ fed-batch: 5 times $\mathrm{H}_{2} \mathrm{O}_{2}$ addition $(5 \times 200 \mu \mathrm{M})$ every $2 \mathrm{~h}, 1 \mathrm{mM}$ substrate (lauric acid), $1 \mu \mathrm{M}$ purified $\mathrm{OleT}, 30^{\circ} \mathrm{C}, 12 \mathrm{~h}$; mean values and standard errors from two parallel experiments

be that $\mathrm{OleT}_{\mathrm{SQ}}$ could be more likely prone to $\mathrm{H}_{2} \mathrm{O}_{2}$ inactivation when used at low enzyme concentrations as in the kinetic studies.

Next, we evaluated the reaction turnover numbers (TONs) of the four FADCs at a higher substrate concentration $(1 \mathrm{mM})$ for longer reaction time $(12 \mathrm{~h})$. A previous study showed that the fed-batch addition of $\mathrm{H}_{2} \mathrm{O}_{2}$ reduced enzyme inactivation and improved catalytic conversion [22]. We thus performed the assay with oneoff and fed-batch supplementation of $\mathrm{H}_{2} \mathrm{O}_{2}$, respectively. As expected, the fed-batch addition of $\mathrm{H}_{2} \mathrm{O}_{2}$ resulted in higher TONs in general (Table 2). The maximum TON of 185 was obtained from OleT $T_{I E}$ while OleT $T_{J H}$ showed the best TON in $1 \mathrm{mM} \mathrm{H}_{2} \mathrm{O}_{2}$. OleT $\mathrm{TE}_{\mathrm{IE}}$ and $\mathrm{OleT}_{\mathrm{JH}}$ seemed to be relatively more resistant to $\mathrm{H}_{2} \mathrm{O}_{2}$ inactivation than $\mathrm{OleT}_{\mathrm{SA}}$ and $\mathrm{OleT}_{\mathrm{SQ}}$, as more than twofold (2.5 and 2.7) TON reductions were observed in $\mathrm{H}_{2} \mathrm{O}_{2}$ batch addition assays of the latter two enzymes compared with their fed-batch addition assays. Nevertheless, the three new FADCs exhibited strong decarboxylation potentials and similar kinetic parameters to $\mathrm{OleT}_{\mathrm{IE}}$. Future reaction process optimization such as in situ generation of $\mathrm{H}_{2} \mathrm{O}_{2}$ [33, 34] or utilization of a redox cascade system [22, 26, 31] could be considered to attenuate the catalyst inactivation by high concentration $\mathrm{H}_{2} \mathrm{O}_{2}$.

\section{Effects of salt concentration on OleT enzymes}

Considering the facts that precipitation of $\mathrm{OleT}_{\mathrm{IE}}$ occurs in low salt buffer [28] and that the OleT enzyme host strains including Jeotgalicoccus, Salinicoccus, and Staphylococcus species are often associated with the property of halophilicity or salt tolerance [35-38], we investigated the effects of salt concentration on the activity and stability of the OleT enzymes. Experimentally, the activities of $\operatorname{OleT}_{\mathrm{JE}}, \mathrm{OleT}_{\mathrm{JH}}, \mathrm{OleT}_{\mathrm{SQ}}$, and $\mathrm{OleT}_{\mathrm{SA}}$ against lauric acid were evaluated under a 
range of $\mathrm{NaCl}$ concentrations. The overall and decarboxylation activities of all four enzymes remained almost unchanged (>90\%) within up to $2 \mathrm{M}$ salt concentration (Fig. 4). However, when $\mathrm{NaCl}$ concentration was $3 \mathrm{M}$ or higher, the activities of all enzymes decreased gradually to different extents, with the only exception of $\mathrm{OleT}_{\mathrm{JE}}$ at $3 \mathrm{M} \mathrm{NaCl}$. However, they all remained at least $22.7 \%$ activity in saturated salt concentration, even up to $66.8 \%$ for $\mathrm{OleT}_{\mathrm{JE}}$.

Next, we examined the salt stability of these OleT enzymes. Upon a 12-h treatment with different salt solution buffers. It is evident that $\mathrm{OleT}_{\mathrm{JE}}$ and $\mathrm{OleT}_{\mathrm{JH}}$ showed much better stabilities than $\mathrm{OleT}_{\mathrm{SQ}}$ and $\mathrm{OleT}_{\mathrm{SA}}$ under all tested $\mathrm{NaCl}$ concentrations. Again, $\mathrm{OleT}_{\mathrm{IE}}$ and $\mathrm{OleT}_{\mathrm{IH}}$ were even able to retain a majority of overall and decarboxylation activities at the saturated concentration (Table 3). Overall, the majority of activity of all four enzymes was maintained in buffer with a $\mathrm{NaCl}$ concentration of $0.5-2 \mathrm{M}$. According to the most widely used standards for halophilicity by Kushner, i.e., extreme halophiles (best in 2.5-5.2 M salt), borderline extreme halophiles (best in 1.5-4.0 M salt), and moderate halophiles (best in 0.5-2.5 M salt) [39-42], which can also be applied to halophilic enzymes $[43,44]$, these P450 FADCs belong to moderate halophilic enzymes.
Table 3 Relative activities of the OleT enzymes after a 12-h treatment at $30{ }^{\circ} \mathrm{C}$ in storage buffer with different $\mathrm{NaCl}$ concentrations

\begin{tabular}{lllll}
\hline Enzymes & \multicolumn{3}{l}{ Relative activities, \% } \\
\cline { 2 - 5 } & $\mathbf{0} \mathbf{M}^{\mathbf{c}}$ & $\mathbf{0 . 5} \mathbf{M}$ & $\mathbf{2} \mathbf{M}$ & Saturated $^{\mathbf{d}}$ \\
\hline OleT $_{\mathrm{JE}}^{\mathrm{a}}$ & $84 \pm 5$ & $104 \pm 2$ & $97 \pm 3$ & $75 \pm 2$ \\
OleT $_{\mathrm{JH}}^{\mathrm{a}}$ & $77 \pm 3$ & 102 & 102 & $79 \pm 11$ \\
OleT $_{\mathrm{SQ}}^{\mathrm{a}}$ & $61 \pm 3$ & $93 \pm 2$ & $65 \pm 6$ & $30 \pm 6$ \\
OleT $_{\mathrm{SA}}^{\mathrm{a}}$ & $57 \pm 5$ & $98 \pm 4$ & $85 \pm 3$ & $56 \pm 4$ \\
OleT $_{\mathrm{JE}}^{\mathrm{b}}$ & $74 \pm 2$ & $95 \pm 3$ & $83 \pm 2$ & $67 \pm 6$ \\
OleT $_{\mathrm{JH}}^{\mathrm{b}}$ & $51 \pm 6$ & $100 \pm 6$ & $90 \pm 1$ & $62 \pm 8$ \\
OleT $_{\mathrm{SQ}}^{\mathrm{b}}$ & $56 \pm 6$ & $112 \pm 3$ & $68 \pm 4$ & $21 \pm 1$ \\
OleT $_{\mathrm{SA}}^{\mathrm{b}}$ & $39 \pm 10$ & $91 \pm 23$ & $90 \pm 3$ & $66 \pm 12$ \\
\hline
\end{tabular}

${ }^{a}$ Relative \% conversion of $C_{12}$ in comparison to the conversion ratio in the standard reaction buffer without pretreatment

b Relative $\%$ of $C_{11} 1$-alkene production in comparison to the conversion ratio in the standard reaction buffer without pretreatment

c "0" means that 1-3 $\mathrm{LL}$ OleT enzymes (in storage buffer) were used in a $200 \mu \mathrm{L}$ $\mathrm{NaCl}$-free reaction buffer

d "Saturated" means an at least $5 \mathrm{M} \mathrm{NaCl}$ concentration

\section{Site-directed mutagenesis of OleT $_{S A}$ fatty acid decarboxylase}

Despite significant advances in understanding of the OleT $_{\mathrm{IE}}$ decarboxylation mechanism $[20,23,28,29,31$, $45,46]$, an effective strategy for engineering a better P450

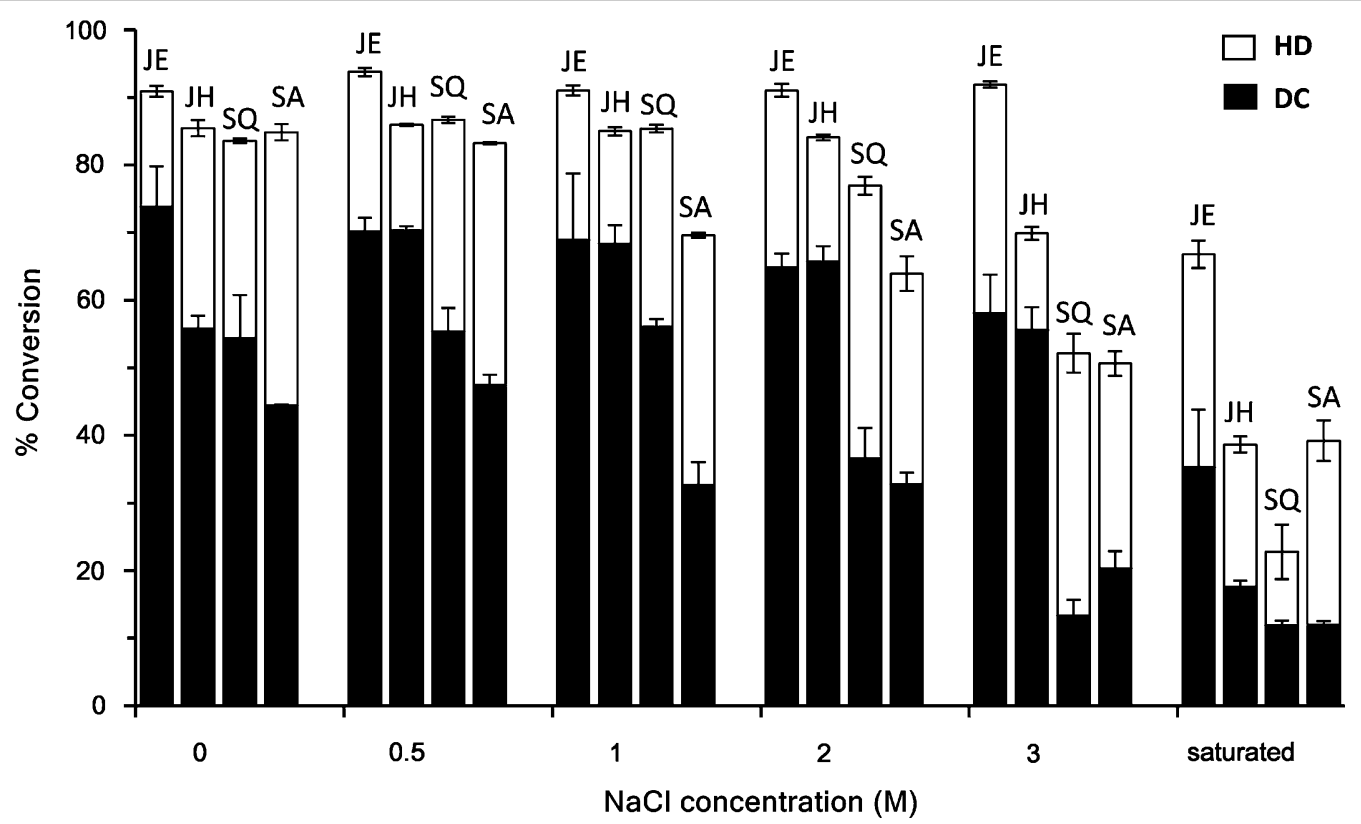

Fig. 4 Effects of different $\mathrm{NaCl}$ concentrations on the activities of $\mathrm{Ole}_{\mathrm{JE}}$ (JE), $\mathrm{OleT}_{J H}(\mathrm{JH}), \mathrm{Ole}_{\mathrm{SQ}}(\mathrm{SQ})$ and $\mathrm{Ole}_{\mathrm{SA}}(\mathrm{SA})$. The hydroxylation (HD) activity was calculated by subtracting the percentage of 1-alkene production from the total substrate conversion ratio. Results are shown as mean \pm SD of two parallel experiments. In a standard assay, 1-3 $\mu \mathrm{L}$ of each OleT enzyme (stored in the storage buffer) was used in $200 \mu \mathrm{L}$ reaction buffer containing different $\mathrm{NaCl}$ concentrations and $200 \mu \mathrm{M}$ lauric acid $\left(\mathrm{C}_{12}\right)$ as substrate 
FADC remains unclear. In this study, the four analogous OleT enzymes with characterized substrate specificity, product distribution and kinetic parameters provided an outstanding opportunity to further dissect the residues important for the decarboxylation activity. Specifically, we discovered, by comparing the crystal structure of $\mathrm{OleT}_{\mathrm{IE}}$ (PDB ID \#: 4L40) and the three modeled structures of the new FADCs, that $\mathrm{OleT}_{\mathrm{JE}}, \mathrm{OleT}_{\mathrm{JH}}, \mathrm{OleT}_{\mathrm{SQ}}$, and $\mathrm{OleT}_{\mathrm{SA}}$ have highly similar substrate-binding pockets with only five out of 19 residues that are different from one another. Comparatively, $\mathrm{OleT}_{\mathrm{JE}}$ and $\mathrm{OleT}_{\mathrm{SA}}$ have the most different substrate-binding pockets (Fig. 5 and Additional file 1: Table S2), which is consistent with their largest difference in catalytic activities among the four tested OleT enzymes towards mid-chain FFA substrates $\left(\mathrm{C}_{8}-\mathrm{C}_{12}\right)$ (Fig. 3 and Table 2).

Following these analyses, we were drawn to mutate Thr47, Ile177, Val319, and Leu405 of OleT ${ }_{\mathrm{SA}}$ into their counterparts in $\mathrm{OleT}_{\mathrm{IE}}$ in consideration of the highest catalytic efficiency of Ole $\mathrm{T}_{\mathrm{JE}}$ and the most different catalytic activities and substrate-binding pockets between these two FADCs (Additional file 1: Table S2). Specifically, we prepared four single mutants including $\mathrm{OleT}_{\mathrm{SA}}-\mathrm{T} 47 \mathrm{~F}$ (M1), $\mathrm{OleT}_{\mathrm{SA}}-\mathrm{I} 177 \mathrm{~L}$ (M2), $\mathrm{OleT}_{\mathrm{SA}}-\mathrm{V} 319 \mathrm{~A}$ (M3) and $\mathrm{OleT}_{\mathrm{SA}}-\mathrm{L} 405 \mathrm{I}$ (M4), and one quadruple mutant $\mathrm{OleT}_{\mathrm{SA}^{-}}$ T47F-I177L-V319A-L405I (M5). Measurements of the in vitro activities of these mutants towards $\mathrm{C}_{8}-\mathrm{C}_{12}$ FFAs (Fig. 6 and Additional file 1: Figure S7) showed that (1) for caprylic acid $\left(\mathrm{C}_{8}\right)$, M1, M2, and M4 displayed enhanced overall and decarboxylation activities, while M3 and M5 exhibited decreased overall and decarboxylation activities when compared to the wild-type $\mathrm{OleT}_{\mathrm{SA}}$; (2) for decanoic acid $\left(\mathrm{C}_{10}\right)$, all four single mutants showed improved overall and decarboxylation activities relative to their parental enzyme, but the activity of the quadruple mutant decreased; and (3) for lauric acid $\left(C_{12}\right)$, all mutants demonstrated $>20 \%$ improvement of substrate conversion ratios compared to the wild-type $\mathrm{OleT}_{\mathrm{SA}}$. However, except for M2, other mutations did not lead to higher levels of 1-undecene $\left(C_{11}\right)$ production.

Collectively, all four tested positions could become the "hot spots" for the future iterative saturation mutagenesis (ISM) and combinatorial active-site saturation testing (CASTing) analyses [47, 48]. Here, the attenuated activity of $\mathrm{OleT}_{\mathrm{SA}}-\mathrm{T} 47 \mathrm{~F}-\mathrm{I} 177 \mathrm{~L}-\mathrm{V} 319 \mathrm{~A}-\mathrm{L} 405 \mathrm{I}$ suggests there might not be an expected synergistic effect between these four residues.

\section{Discussion}

In this study, we have expressed, purified and characterized three new P450 FADCs in vitro, namely, $\mathrm{OleT}_{\mathrm{JH}}$, $\mathrm{OleT}_{\mathrm{SQ}}$, and $\mathrm{OleT}_{\mathrm{SA}}$ that can efficiently catalyze the
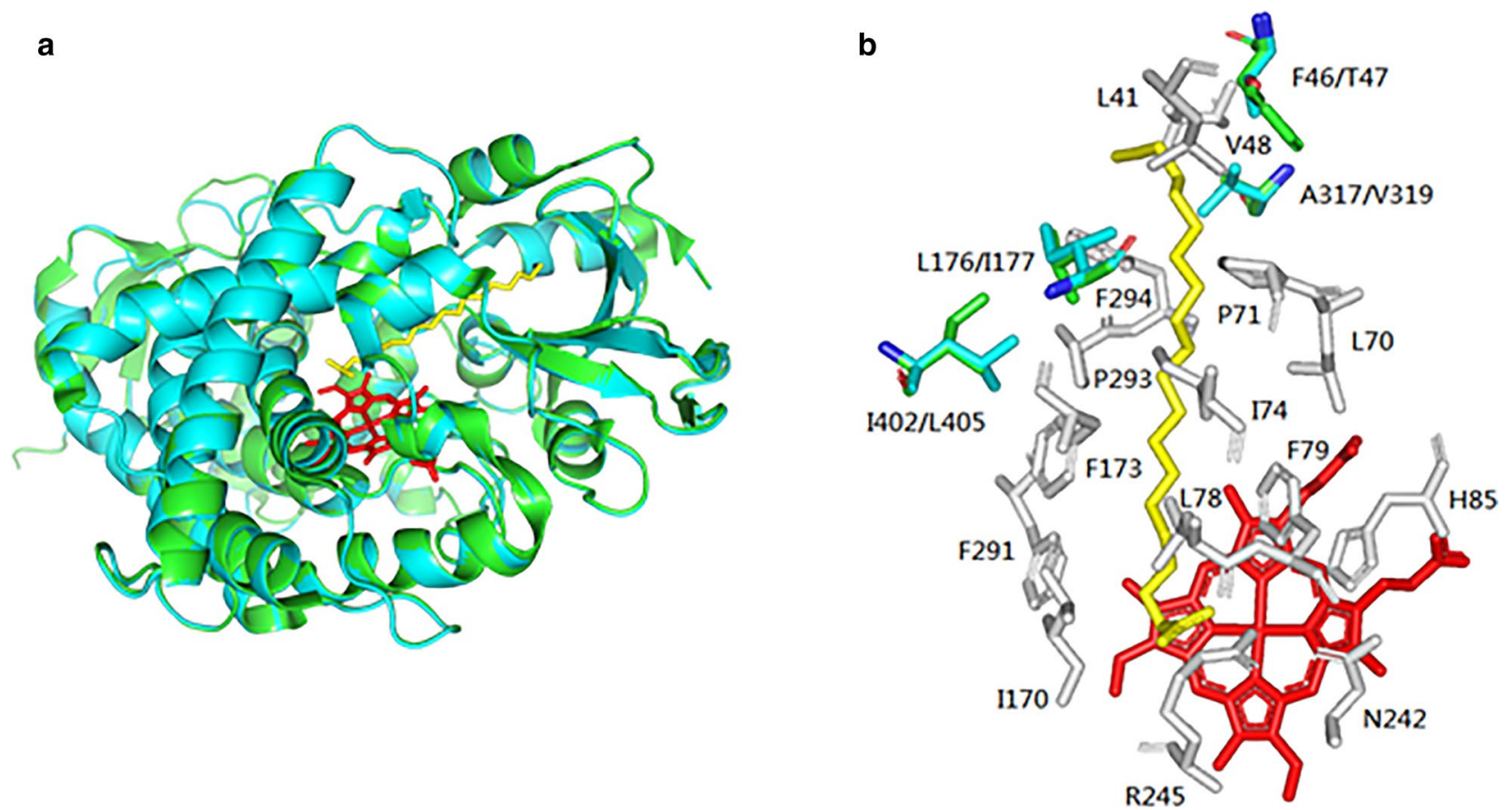

Fig. 5 Comparison of overall structures and the substrate-binding pockets of $\mathrm{OleT}_{\mathrm{SA}}$ and OleT $\mathrm{JE}$. $\mathbf{a}$ The crystal structure of C20:0 fatty acid-bound OleT $_{\text {JE }}$ (PDB: 4L40) is shown in green and the modeled structure of OleT $_{S A}$ using Phyre ${ }^{2}$ software in cyan. $\mathbf{b}$ Comparison of substrate-binding pockets between OleT $_{\mathrm{JE}}$ (in green) and $\mathrm{OleT}_{\mathrm{SA}}$ (in cyan). Red: heme; yellow: eicosanoic acid; gray: the same active site residues in OleT $\mathrm{JE}_{\mathrm{E}}$ and $\mathrm{OleT}_{\mathrm{SA}}$ 


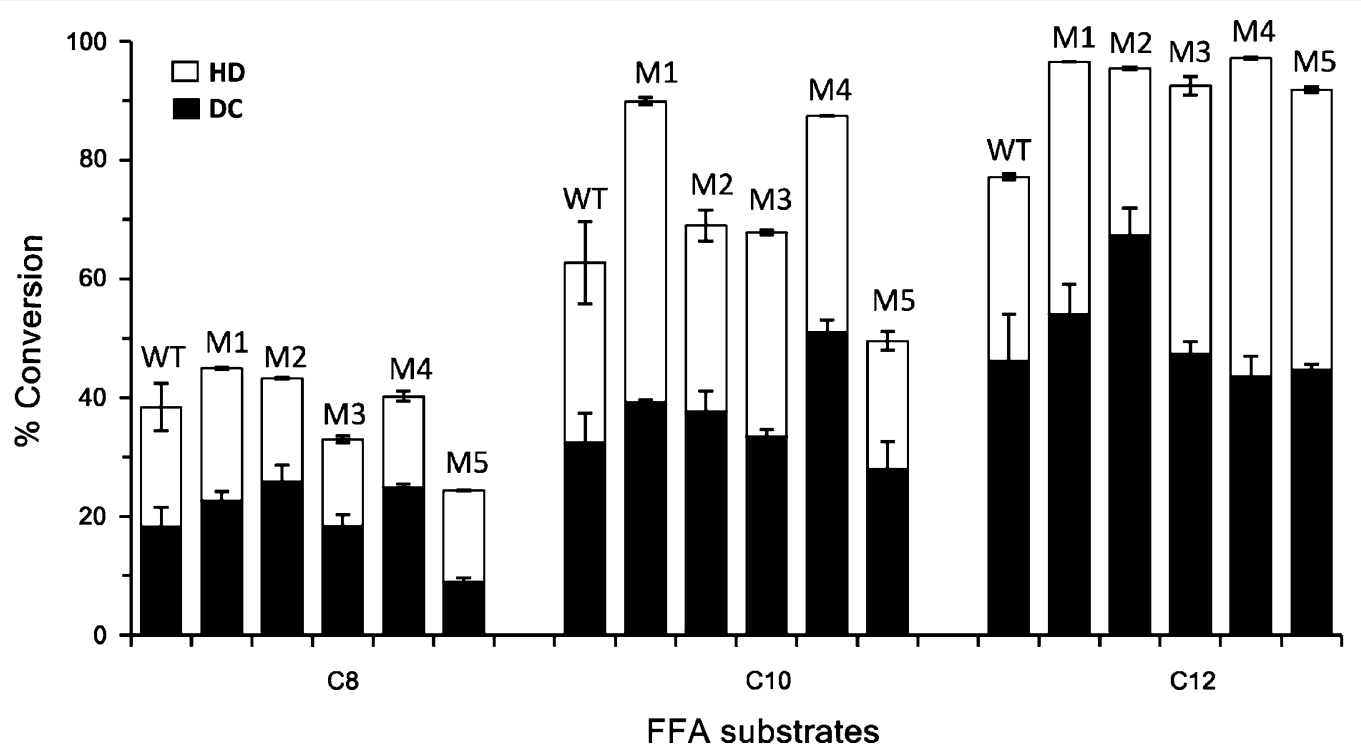

Fig. 6 Comparison of the decarboxylation (DC) and hydroxylation (HD) activities between $\mathrm{OleT}_{S A}(\mathrm{WT})$ and its mutants. The $\mathrm{C}_{8}-\mathrm{C}_{12}$ FFAs were used as substrates for wild-type OleT $_{S A}$ (WT) and the mutants including T47F (M1), I177L (M2), V319A (M3), L405I (M4) and T47F-1177L-V319A-L405I (M5). The hydroxylation (HD) activity was calculated by subtracting the percentage of 1-alkene production from the total substrate conversion ratio. Results are shown as mean \pm SD of two parallel experiments

conversions from FFAs to 1-alkenes. Among all substrates $\left(\mathrm{C}_{8}-\mathrm{C}_{20}\right.$ FFAs), these three new enzymes exhibit higher decarboxylation activity towards lauric acid and myristic acid, with the lower decarboxylation activity for eicosanoic acid. The strict carbon chain length dependence for decarboxylative activity is consistent with the well-characterized FADCs OleT $_{\text {IE }}$ [11] and CYP-Sm46 29 [12], which further emphasize the importance of substrate identity in achieving the desirable reaction type. Our finding that $\beta$-hydroxyl product rather than $\alpha$-hydroxyl product is the major by-product in all alkene-generating catalysis here supports the notion that $\mathrm{C}_{\beta}-\mathrm{H}$ abstraction may be one of the key factors that affect the production of 1-alkenes, which is well in line with the proposed mechanism by Makris et al. that Compound I (an iron(IV)-oxo cation radical) abstracts the $\mathrm{C}_{\beta}-\mathrm{H}$ atom to initiate the decarboxylation of fatty acids [20].

In general, salt solutions could impact protein folding mode, and hence the conformational stability of proteins [49-51]. We found that $\operatorname{OleT}_{\mathrm{JH}}, \mathrm{OleT}_{\mathrm{SQ}}$, OleT $\mathrm{SA}$ and $\mathrm{OleT}_{\mathrm{IE}}$ exhibit optimal activities as well as stabilities in salt solutions with the $\mathrm{NaCl}$ concentration ranging from 0.5 to $2 \mathrm{M}$ (2.9-11.7\%), thus classifying these FADCs as moderate halophilic enzymes. This seems to be consistent with the halophilic property of their native host microorganisms which have shown optimal growth at the $\mathrm{NaCl}$ strength of 2-3\% (Jeotgalicoccus halophilus) [38], 3\% (Salinicoccus qingdaonensis) [37] and 2.1-7\%
(Staphylococcus aureus) [52], respectively, thus being classified as moderate halophilic bacterial strains.

However, not all halophiles bear halophilic (P450) proteins. Two other P450 enzymes CYP102A26 [53] and CYP116B62 [54] from the halophilic bacteria Pontibacillus halophilus and Halomonas sp. NCIMB 172 exhibited decreased enzymatic activity in the presence of $\mathrm{NaCl}$ at $0.025 \mathrm{M}$ and $0.05 \mathrm{M}$, respectively. This difference may be related to the different strategies how halophiles adapt to high salinity ("salt in" or "salt out"). Most halophilic bacteria use a "salt out" strategy to exclude salt to protect their non-halophilic enzymes [40]. While in a 'salt in' strategy that is used primarily by haloarchaea to accumulate high concentrations of salt, their enzymes have been examined to tolerate or even require 4-5 M salt [41].

Previous studies suggested that hydrogen bonds between negatively charged side chains and water molecules are critical for halophilic proteins to maintain a stable hydration shell under water-limited conditions $[55,56]$. In a detailed study comparing 15 pairs of homologous non-halophilic and halophilic proteins ( $\gamma$-glutamyltranspeptidases), it was shown that halophilic proteins tend to have increased number of acidic amino acids in their total surface residues, and within the whole protein sequences [57]. Thus, the ratio of acidic amino acids (Glu/Asp) in the total protein sequence of a halophilic protein has been considered as an important parameter to distinguish it from non-halophilic proteins from the same class of enzymes [39-41]. Notably, this 
is the first time that 'halophilic P450 enzymes' has been proposed for the need of salt to maintain the enzyme activity and stability. We subsequently calculated the ratios of acidic amino acids (Glu/Asp) in the total protein sequences for the four P450 halophilic FADCs. An average ratio of $14 \%\left(\mathrm{OleT}_{\mathrm{JE}}: 14.5 \%\right.$, $\mathrm{OleT}_{\mathrm{JH}}: 14.2 \%, \mathrm{OleT}_{\mathrm{SQ}}$ : $14.6 \%$, $\mathrm{OleT}_{\mathrm{SA}}: 14.5 \%$ ) (Figure $\mathrm{S} 8$ ) was obtained, which is comparable to a halophilic alkaline phosphatase (TAP: 14.0\%) from Halomonas sp. 593 [58] and significantly higher than those non-halophilic P450 enzymes such as $\mathrm{P}_{450} \mathrm{BS}_{\beta}(11.7 \%)$ and $\mathrm{P}^{4} 50_{\mathrm{SP} \alpha}(11.8 \%)[14,17]$. However, detailed salt-tolerance mechanisms used by these P450s have yet to be elucidated. Furthermore, we suggest that a halophilic bacterial host for P450 FADCs could be engineered for efficient production of 1-alkenes based on the halophilic property of these CYP152 peroxygenases.

In our mutagenesis analyses, according to the catalytic activity profiles of the $\mathrm{OleT}_{\mathrm{SA}}$ mutants, T47F mutation seemed to show more impact on the conversion of longer-chain FFAs (a 1.3-fold increase toward $\mathrm{C}_{12}$ ) than on that of the shorter chain C8 fatty acid (1.2-fold increase). Considering this residue is located at the top (the alkyl end) of the binding pocket, the bulky nature of the Phe side chain may help push an improved docking and binding of the longer chain fatty acid substrates. However, it is too far to the active site to make an impact on the chemo-selectivity of the enzymes (Fig. 5 and Additional file 1: Figure S7). Another mutation I177L is located in a structurally disordered region, the F-G loop. This distal loop area has been recently studied by Makris et al. suggesting its necessity for both substrate positioning and product release [45]. A single amino acid change at this site (L176G) switched OleT $\mathrm{IE}_{\mathrm{IE}}$ from a decarboxylase to a hydroxylase [45]. Our results with the mutant $\mathrm{OleT}_{\mathrm{SA}}-\mathrm{I} 177 \mathrm{~L}$ displayed improved catalytic conversion as well as the DC over HD selectivity towards all tested substrates, in particular the mid-chain fatty acid $\mathrm{C}_{12}$ (Additional file 1: Figure S7), demonstrating the crucial role of this leucine residue in OleT enzymes for the decarboxylation reaction. After all, the Ile to Leu replacement is only a minor structural change; the data suggest a delicate and accurate substrate positioning is required for regio- and chemo-selectivity of these P450 FADCs. As for the mutation L405I, since it is more into the middle and towards the bottom (the acyl end) of the binding pocket, the mutant $\mathrm{OleT}_{\mathrm{SA}}$-L405I exhibited more prominent effect on the $\mathrm{DC} / \mathrm{HD}$ selectivity towards the shorter-chain $\mathrm{C}_{8}$ fatty acid than by the other mutants (Additional file 1: Figure S7). However, despite the overall modulation of these mutants on the catalytic conversion and reaction selectivity of $\mathrm{OleT}_{\mathrm{SA}}$, none of them are superior to Ole $\mathrm{T}_{\mathrm{IE}}$ in catalytic activity or decarboxylation selectivity. It was also difficult to see a synergistic effect from the quadruple mutant (Fig. 6).

These results together with previous studies [12, 24-26, 31 ], suggest that it remains challenging to rationally engineer a better substrate-binding pocket in OleT enzymes for better overall and decarboxylation activities. The residues that are distant from the substrate-binding site may be worth more attention in the future, which apparently requires a high-throughput screening (HTS) assay to enable the directed evolution [59-61] efforts. The development of such a HTS method is currently ongoing in our laboratory. Better unnatural FADCs would not only benefit the mechanistic understanding, but also increase the opportunity for industrialization of the intriguing $\alpha$-olefin-producing enzymes.

\section{Conclusions}

In this study, we biochemically characterized three new P450 FADCs that are able to efficiently decarboxylate a range of saturated fatty acids $\left(\mathrm{C}_{8}-\mathrm{C}_{20}\right)$, with $\mathrm{OleT}_{\mathrm{IH}}$ showing the decarboxylation activities, kinetic parameters, as well as salt tolerance and stability that are comparable to $\mathrm{OleT}_{\mathrm{JE}}$. All four tested P450 FADCs exhibited moderate halophilicity unanimously. Further mutagenesis analysis based on protein sequence and activity comparisons of $\mathrm{OleT}_{\mathrm{JE}}$ and $\mathrm{OleT}_{\mathrm{SA}}$ provides more insights into the unique catalytic mechanism of P450 FADCs. The results lay out an advanced foundation for the future engineering efforts on this class of moderate halophilic P450 enzymes in order to produce desirable carbon chain length 1-alkenes efficiently.

\section{Methods \\ Materials}

The strains of E. coli DH5a and BL21(DE3) were preserved by our laboratory. All chemicals and antibiotics were obtained from TCI (Shanghai, China), Solarbio (Beijing, China), Sigma Aldrich (St. Louis, MO, USA) or Thermo Scientific (Shanghai, China). I- $5^{\mathrm{TM}} 2 \times$ HighFidelity Master Mix and Trelief SoSoo Cloning Kit were obtained from TsingKe (Beijing, China). Plasmid Miniprep Kit from TsingKe was used to prepare plasmid DNA from E. coli DH5 . ClonExpress II One-Step Cloning Kit was purchased from Vazyme (Nanjing, China). The $10 \times$ QuickRun $^{\mathrm{TM}}$ Fast Running Buffer and FlexiRun ${ }^{\mathrm{TM}}$ premixed gel solution for SDS-PAGE were obtained from MDBio (Xinbei, China). Ni-NTA resin used for protein purification was supplied by Sangon Biotech (Shanghai, China). PD-10 desalting columns were purchased from GE Healthcare (Piscataway, NJ, USA). Millipore Amicon Ultra centrifugal filters were obtained from Millipore (Billerica, MA, USA). 


\section{Bioinformatics analysis}

The CYP152 family protein sequences were BLAST searched against the protein database on National Center for Biotechnology Information (NCBI) based on the query sequences of $\operatorname{OleT}_{\mathrm{JE}}(\mathrm{CYP} 152 \mathrm{~L} 1)$ and CYPSm46 29 (CYP152L2). Proteins with a sequence identity greater than $60 \%$ were selected and the sequence alignments were performed using ClustalW (https://www. genome.jp/tools-bin/clustalw). The phylogenetic tree was built using the neighbor-joining (NJ) method in MEGA 7.0 package. Bootstrap values shown next to the branches were computed from 1000 bootstrap tests.

\section{Molecular cloning and protein purification}

The gene sequences encoding $\mathrm{OleT}_{\mathrm{JH}}$ from Jeotgalicoccus halophilus (CYP152L1_ortholog, GenBank accession number: WP_092595307), $\mathrm{OleT}_{\mathrm{SQ}}$ from Salinicoccus qingdaonensis (CYP152L8, GenBank accession number: WP_092983663), and OleT $_{\mathrm{SA}}$ from Staphylococcus aureus (CYP152L7, GenBank accession number: WP_049319149) were codon-optimized and synthesized by Qinglan (Yixing, China), and then cloned into the vector $\mathrm{pET} 28 \mathrm{~b}$ via the $\mathrm{NdeI} / \mathrm{Xhol}$ restriction sites for expression of the $\mathrm{N}$-terminal $\mathrm{His}_{6}$-tagged proteins. The generation of single mutation gene constructs of $\mathrm{OleT}_{\mathrm{SA}^{-}}$ T47F, OleT $\mathrm{SA}_{\mathrm{A}}-\mathrm{I177L}$, $\mathrm{OleT}_{\mathrm{SA}}-\mathrm{V} 319 \mathrm{~A}, \mathrm{OleT}_{\mathrm{SA}}-\mathrm{L} 405 \mathrm{I}$ was achieved by site-directed mutagenesis via overlap extension PCR [62]. The sequences of primers used in this study are listed in Additional file 1: Table S1). All cloned sequences were confirmed by DNA sequencing at Sangon Biotech (Shanghai, China), and then used to transform $E$. coli BL21 (DE3) for protein expression and purification.

The E. coli BL21 (DE3) cells carrying the recombinant expression vector were grown $12 \mathrm{~h}$ at $37{ }^{\circ} \mathrm{C}$ with shaking at $220 \mathrm{rpm}$ and then used as seed cultures to inoculate (1:100 ratio) a modified Terrific Broth medium containing $4 \%$ glycerol, a rare salt solution [26] and $1 \mathrm{mM}$ thiamine. Cells were grown at $37{ }^{\circ} \mathrm{C}$ for $3-4 \mathrm{~h}$ until the optical density at $600 \mathrm{~nm}\left(\mathrm{OD}_{600}\right)$ reached $0.8-1.0$, to which $\delta$-aminolevulinic acid (5-ALA, $0.5 \mathrm{mM}$ ) and isopropyl $\beta$-D-1-thiogalactopyranoside (IPTG, $0.2 \mathrm{mM}$ ) were added, and followed by $24 \mathrm{~h}$ of cultivation at $18{ }^{\circ} \mathrm{C}$. The cells were harvested $\left(6000 \times g, 4{ }^{\circ} \mathrm{C}, 10 \mathrm{~min}\right)$ and then stored at $-80^{\circ} \mathrm{C}$.

Purification of His-tagged OleT enzymes was carried out as described by Liu et al. [26] with slight modifications. The cell pellets stored at $-80{ }^{\circ} \mathrm{C}$ were taken out to melt at room temperature, then all the following steps were performed at $4{ }^{\circ} \mathrm{C}$. Briefly, the cell pellets were re-suspended in $50 \mathrm{~mL}$ lysis buffer $(\mathrm{pH} 8.0$, $50 \mathrm{mM} \mathrm{NaH}{ }_{2} \mathrm{PO}_{4}, 300 \mathrm{mM} \mathrm{NaCl}, 10 \%$ glycerol, $10 \mathrm{mM}$ imidazole) through vortexing and were then disrupted by ultrasonication. Cell-free lysate was obtained by centrifuging at $10,000 \times g$ for $1 \mathrm{~h}$ at $4{ }^{\circ} \mathrm{C}$, to which $1-2 \mathrm{~mL}$ Ni-NTA resin slurry was added and mixed gently for $2 \mathrm{~h}$. The mixture was loaded onto an empty column and washed with approximately $200 \mathrm{~mL}$ wash buffer $(\mathrm{pH} \mathrm{8.0,}$ $50 \mathrm{mM} \mathrm{NaH}{ }_{2} \mathrm{PO}_{4}, 300 \mathrm{mM} \mathrm{NaCl}, 10 \%$ glycerol, $20 \mathrm{mM}$ imidazole) until no protein was eluted in flow-through. His-tagged proteins bound to Ni-NTA resin were eluted with $10 \mathrm{~mL}$ elution buffer $\left(\mathrm{pH} 8.0,50 \mathrm{mM} \mathrm{NaH}{ }_{2} \mathrm{PO}_{4}\right.$, $500 \mathrm{mM} \mathrm{NaCl}, 10 \%$ glycerol, $250 \mathrm{mM}$ imidazole). The eluents were concentrated with an Amicon Ultra centrifugal filter (30 kDa cutoff) and were buffer-exchanged into storage buffer ( $\mathrm{pH} 7.4,50 \mathrm{mM} \mathrm{NaH}_{2} \mathrm{PO}_{4}, 500 \mathrm{mM} \mathrm{NaCl}$, $10 \%$ glycerol). The final purified proteins were flash frozen by liquid nitrogen and stored at $-80^{\circ} \mathrm{C}$ for later use.

\section{UV-visible spectroscopic characterization and determination of enzyme concentration}

The analysis of the UV-visible spectroscopic properties was carried out as described by $\mathrm{Xu}$ et al. with minor modifications [12]. In general, the UV-visible spectroscopic properties of the His-tagged proteins were performed on a Cary $60 \mathrm{UV}$-visible spectrophotometer (Varian, UK). For preparation of the dithionite-reduced ferrous- $\mathrm{CO}$ complex of each enzyme, the purified ferric enzymes were diluted in Storage buffer $(\mathrm{pH} 7.4$, $50 \mathrm{mM} \mathrm{NaH}_{2} \mathrm{PO}_{4}, 500 \mathrm{mM} \mathrm{NaCl}, 10 \%$ glycerol) and subjected to slow $\mathrm{CO}$ bubbling for $40-50 \mathrm{~s}$ for initial scan at $350-600 \mathrm{~nm}$ to record the spectrum of the resting-state CO-bound proteins, and then followed by sufficient reduction of the protein by sodium dithionate to obtain the CO-bound reduced difference spectrum. The protein concentration was calculated by the reduced differential extinction coefficient $\varepsilon_{450-490} \mathrm{~nm}$ of $91,000 \mathrm{M}^{-1} \mathrm{~cm}^{-1}$ for the functional P450 concentration [63].

\section{In vitro enzymatic assay}

Typical assays containing $1 \mu \mathrm{M}$ of each enzyme $\left(\mathrm{OleT}_{\mathrm{IE}}\right.$, OleT $_{\mathrm{JH}}, \mathrm{OleT}_{\mathrm{SQ}}, \mathrm{OleT}_{\mathrm{SA}}$ or its individual mutant), $200 \mu \mathrm{M}$ fatty acid substrate $\left(\mathrm{C}_{8}-\mathrm{C}_{20}\right.$ FFAs prepared from stock solution in DMSO $(20 \mathrm{mM})$ ), and $220 \mu \mathrm{M} \mathrm{H}_{2} \mathrm{O}_{2}$ in $200 \mu \mathrm{L}$ of buffer (pH 7.4, $50 \mathrm{mM} \mathrm{NaH}{ }_{2} \mathrm{PO}_{4}, 500 \mathrm{mM} \mathrm{NaCl}, 10 \%$ glycerol) were carried out at $30{ }^{\circ} \mathrm{C}$ for $2 \mathrm{~h}$. This amount of hydrogen peroxide was proven to be sufficient (Additional file 1: Figure S9). Reactions were quenched by adding $20 \mu \mathrm{L} 10 \mathrm{M} \mathrm{HCl}$, then heptadecanoic acid $\left(\mathrm{C}_{17}\right)$ was added as internal standard and the mixture was extracted by $150 \mu \mathrm{L}$ ethyl acetate. The organic phase was analyzed by gas chromatography (GC) as described below.

For detection of 1-heptene $\left(C_{7}\right)$ product generated from caprylic acid $\left(\mathrm{C}_{8}\right)$ fatty acid decarboxylation, $1.5 \mathrm{~mL}$ polytetrafluorethylene (PTFE) septum-sealed glass bottles were used for $500 \mu \mathrm{L}$ reaction systems containing 
$1 \mu \mathrm{M}$ enzyme, $200 \mu \mathrm{M} \mathrm{C} \mathrm{C}_{8}$ fatty acid substrate, $220 \mu \mathrm{M}$ $\mathrm{H}_{2} \mathrm{O}_{2}$, and $200 \mu \mathrm{M}$ 1-nonene $\left(\mathrm{C}_{9}\right)$ as the internal standard. The reactions were incubated at $30{ }^{\circ} \mathrm{C}$ for $2 \mathrm{~h}$ with shaking at $100 \mathrm{rpm}$. Then the reactions were placed at $4{ }^{\circ} \mathrm{C}$ for $12 \mathrm{~h}$ to stop reactions prior to heating at $40{ }^{\circ} \mathrm{C}$ for $20 \mathrm{~min}$ for headspace sampling using a gas-tight Hamilton syringe for GC-MS analysis. Different concentrations of the authentic 1-heptene standard incubated under the same conditions as reactions were analyzed using the same GC-MS method to obtain the standard curve. After headspace sampling, the remaining $C_{8}$ substrate in reactions was extracted as above described for further GC measurement and analysis.

\section{Effects of salt concentration}

Effect of salt $(\mathrm{NaCl})$ was tested by measuring the decarboxylation activity in the reaction buffer $(\mathrm{pH} 7.4,50 \mathrm{mM}$ $\mathrm{NaH}_{2} \mathrm{PO}_{4}, 10 \%$ glycerol) containing different concentrations of $\mathrm{NaCl}$ ranging from $0 \mathrm{M}, 0.5 \mathrm{M}, 1 \mathrm{M}, 2 \mathrm{M}, 3 \mathrm{M}$ to saturated salinity $(>5 \mathrm{M})$ at $30{ }^{\circ} \mathrm{C}$ for $2 \mathrm{~h}$. To determine their halostability, these enzymes were pre-incubated in buffer ( $\mathrm{pH}$ 7.4, $50 \mathrm{mM} \mathrm{NaH} \mathrm{PO}_{4}, 10 \%$ glycerol) containing different concentrations of $\mathrm{NaCl}(0 \mathrm{M}, 0.5 \mathrm{M}$, $2 \mathrm{M}$, and saturated salt solution) at $30^{\circ} \mathrm{C}$ for $12 \mathrm{~h}$ with non-treated enzyme as the control. The residual activities were then measured as in typical assays. For all reactions in salt effect experiments, $1-3 \mu \mathrm{L}$ of enzymes stored at $-80{ }^{\circ} \mathrm{C}$ in storage buffer (pH 7.4, $50 \mathrm{mM} \mathrm{NaH}_{2} \mathrm{PO}_{4}$, $500 \mathrm{mM} \mathrm{NaCl}, 10 \%$ glycerol) were used in $200 \mu \mathrm{L}$ reaction systems containing different concentrations of salt.

\section{Steady-state kinetic analysis}

Determination of the steady-stated kinetic parameters was carried out as described by $\mathrm{Xu}$ et al. with minor modifications [12]. Briefly, 15-40 nM enzyme was used with a range of different substrate $\left(\mathrm{C}_{12}\right)$ concentrations in a $1 \mathrm{~mL}$ reaction system $\left(\mathrm{pH} 7.4,50 \mathrm{mM} \mathrm{NaH} \mathrm{PO}_{4}\right.$, $500 \mathrm{mM} \mathrm{NaCl}, 10 \%$ glycerol). The reaction was initiated by adding an excess amount of $\mathrm{H}_{2} \mathrm{O}_{2}(330 \mu \mathrm{M})$ at $30{ }^{\circ} \mathrm{C}$. Aliquots $(200 \mu \mathrm{L})$ of reactions were removed and quenched at fixed time points $(0,0.5,1,2 \mathrm{~min})$ by adding $20 \mu \mathrm{L} 10 \mathrm{M} \mathrm{HCl}$ for reaction termination. Sample extraction and analysis were performed the same as above for GC analysis. Initial rates were calculated in terms of the substrate consumption by each enzyme. Kinetic analyses were performed using OriginPro 8.5 program.

\section{Homology modeling}

The 3D structures of $\mathrm{OleT}_{\mathrm{IH}}, \mathrm{OleT}_{\mathrm{SQ}}$ and $\mathrm{OleT}_{\mathrm{SA}}$ were generated by using the homology modeling function of Phyre $^{2}$ (Protein Homology/analogy Recognition Engine V2.0) program. The structure of $\operatorname{OleT}_{\mathrm{JE}}$ (PDB ID \#:
4L40) and the modeled structures were analyzed with PyMOL (V2.2.0).

\section{Analytical methods}

The hydrocarbon and fatty acid samples were analyzed by the methods from Guan et al. [64]. The Agilent $7890 \mathrm{~B}$ gas chromatograph equipped with a capillary column HP-5 (Agilent Technologies, Santa Clara, CA, USA; cross-linked polyethylene glycerol, i.d. $0.25 \mu \mathrm{m}$ film thickness, $30 \mathrm{~m}$ by $0.32 \mathrm{~mm}$ ) was used for analyses. The flow rate of helium was set to $1 \mathrm{~mL}$ per min. The oven program was set initially at $40{ }^{\circ} \mathrm{C}$ for $4 \mathrm{~min}$, then increased to $280{ }^{\circ} \mathrm{C}$ by the rate of $10{ }^{\circ} \mathrm{C}$ per min and held for $5 \mathrm{~min}$. The injecting temperature was set to $280{ }^{\circ} \mathrm{C}$ under splitless injection conditions with $1 \mu \mathrm{L}$ injection volume. Under these conditions, the retention times and signal intensity of fatty acids and terminal alkenes products were determined and compared with corresponding authentic standards (FFAs: $\mathrm{C}_{8}-\mathrm{C}_{20}$, 1-alkenes: $\left.\mathrm{C}_{7}-\mathrm{C}_{19}\right)$ and the internal standard (1-heptadecanoic acid $\left(\mathrm{C}_{17}\right)$ ). For analyses of $\mathrm{GC}-\mathrm{MS}$, the gas chromatography was equipped with an Agilent 5975C MSD single quadrupole mass spectrometer operated under electron ionization mode at $70 \mathrm{eV}$ in the scan range of $50-500 \mathrm{~m} / z$. For detection of $\alpha$ - and $\beta$-hydroxyl products of myristic acid, the samples extracted from the myristic acid $\left(\mathrm{C}_{14}\right)$ reactions were derivatized with an equal volume of $\mathrm{N}, \mathrm{O}$-bis (trimethylsilyl) trifluoroacetamide (BSTFA) with $1 \%$ trimethylchlorosilane at $72{ }^{\circ} \mathrm{C}$ for 15 min before GC-MS analysis. The GC-MS analysis used the previous protocol adapted from Rude et al. with the Agilent J\&W DB-5MS column (i.d. $0.25 \mu \mathrm{m}$ film thickness, $50 \mathrm{~m}$ by $0.25 \mathrm{~mm}$ ). Peak identity was determined by comparisons of the retention time and fragmentation pattern with the authentic standard compounds where available and to National Institute of Standards and Technology, USA mass spectral database. We found that the sum of all products $(\alpha-, \beta$-hydroxy myristic acids and 1 -tridecene) almost accounted for $99 \%$ of the substrate consumption, so we subtracted the 1-alkene production from the total substrate consumption to quantify the percentage of hydroxylated products for all substrates unless otherwise stated. For detection of 1-heptene $\left(\mathrm{C}_{7}\right)$ product produced by caprylic acid $\left(\mathrm{C}_{8}\right)$ decarboxylation, $500 \mu \mathrm{L}$ of the reaction headspace sample was injected into GC-MS system with a Hamilton needle syringe and analyzed by authentic standard curves as well as reaction controls. The oven temperature procedure was set at follows: $40^{\circ} \mathrm{C}$ for $2 \mathrm{~min}$, then increased to $100{ }^{\circ} \mathrm{C}$ by $5^{\circ} \mathrm{C} \mathrm{min}^{-1}$ and held for $2 \mathrm{~min}$. 


\section{Additional files}

Additional file 1: Figure S1. Protein sequence alignment of the P450 fatty acid decarboxylases OleT JE from Jeotgalicoccus sp. ATCC 8456 (GenBank accession number: ADW41779) and CYP-Sm46 $\triangle 29$ (with the $\mathrm{N}$-terminal redundant 29 amino acids deleted) from Staphylococcus massiliensis S46 (GenBank accession number:WP_039990689), with the newly identified FADCs of OleT ${ }_{J H}$ from Jeotgalicoccus halophilus (GenBank accession number:WP_092595307), OleT SQ from Salinicoccus qingdaonensis (GenBank accession number:WP_092983663), and OleT SA from Staphylococcus aureus (GenBank accession number:WP_049319149). The orange stars indicate the residues $(79 \mathrm{~F}, 85 \mathrm{H}, 170 \mathrm{l}, 245 \mathrm{R})$ that have been reported to be important for decarboxylation by P450 OleT JE. The blue stars indicate the key different amino acid residues. Figure S2. SDS-PAGE analysis of the purified $\mathrm{His}_{6}$-tagged OleT $\mathrm{T}_{\mathrm{JH}}$ (lane A), OleT $\mathrm{SQ}_{\mathrm{SQ}}$ (lane B), OleT $\mathrm{T}_{\mathrm{SA}}$ (lane C), and protein marker (M). Figure S3. UV-visible spectra of $\operatorname{OleT}_{J E}(A), \operatorname{OleT}_{J H}(B)$, OleT $_{S Q}(C)$ and $O_{\text {IeT }}$ SA $(D)$. The purified enzymes were diluted in buffer $(\mathrm{pH}$ 7.4) containing $50 \mathrm{mM} \mathrm{NaH}_{2} \mathrm{PO} 4,500 \mathrm{mM} \mathrm{NaCl}$ and 10\% glycerol. (Black lines show the spectra for the oxidized ferric form of CYPs and red lines show the spectra for the $\mathrm{Na}_{2} \mathrm{~S}_{2} \mathrm{O}_{4}$-reduced ferrous- $\mathrm{CO}$ complex of CYPs; Insets exhibit the reduced $\mathrm{CO}$-bound difference spectra of P450 enzyme). Figure S4. Kinetic curves of $\mathrm{OleT}_{\mathrm{JE},}, \mathrm{OleT}_{\mathrm{JH}}, \mathrm{OleT}_{\mathrm{SQ}}$ and $\mathrm{OleT}_{\mathrm{SA}}$ against their optimal substrate (lauric acid) were fitted to Michaelis-Menten equation respectively. (A) Lauric acid $\left(\mathrm{C}_{12}\right)$ substrate consumption rates by $\mathrm{OleT}_{\mathrm{JE}}$; (B) Lauric acid $\left(\mathrm{C}_{12}\right)$ substrate consumption rates by $\mathrm{OleT}_{J H^{;}}(\mathrm{C})$ Lauric acid $\left(C_{12}\right)$ substrate consumption rates by Ole $T_{S Q} ;(D)$ Lauric acid $\left(C_{12}\right)$ substrate consumption rates by OleT $_{\mathrm{SA}}$. The steady state kinetic parameters were calculated using OriginPro 8.5 and are summarized in Table 2. Figure S5.

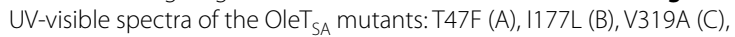
L405I (D) and T47F/I177L/N319A/L405I (E). The purified enzymes were diluted in buffer ( $\mathrm{pH}$ 7.4) containing $50 \mathrm{mM} \mathrm{NaH}_{2} \mathrm{PO}_{4}, 500 \mathrm{mM} \mathrm{NaCl}$ and $10 \%$ glycerol, respectively. (Black lines show the spectra for the oxidized ferric form of CYPs and red lines show the spectra for the $\mathrm{Na}_{2} \mathrm{~S}_{2} \mathrm{O}_{4}$-reduced ferrous-CO complex of CYPs; Insets exhibit the reduced CO-bound difference spectra of P450 enzyme). Figure S6. SDS-PAGE analysis of the purified $\mathrm{His}_{6}$-tagged mutants, including T47F (lane A), I177L (lane B), V319A (lane C), L405I (lane D), T47F/I177L/N319A/L405I (lane E), and protein marker (M). Figure S7. Decarboxylation (DC) versus hydroxylation (HD) activities (ratios) of Ole $T_{\text {SA }}$ (WT) and its mutants including T47F (M1), 1177L (M2), V319A (M3), L405I (M4), and T47F-I177L-V319A-L405I (M5) towards mid-chain fatty acids $\left(C_{8}-C_{12}\right)$. Figure $\mathbf{S 8}$. Analysis of acidic amino acids (aspartic acid in red and glutamic acid in cyan) in the protein structure of

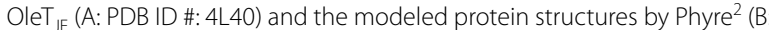
$\mathrm{OleT}_{\mathrm{JH}} ; \mathrm{C}: \mathrm{OleT}_{\mathrm{SQ}} ; \mathrm{D}$ : OleT $\left.\mathrm{T}_{\mathrm{SA}}\right)$. Figure S9. The effect of $\mathrm{H}_{2} \mathrm{O}_{2}$ concentration on substrate conversion ratios for four FADCs (A: OleT $\mathrm{JE}_{\mathrm{J}}$ B: OleT $\mathrm{JH}_{\mathrm{H}} ; \mathrm{C}: \mathrm{OleT}_{\mathrm{SQ}}$; D: $\left(\mathrm{leT}_{\mathrm{SA}}\right)$ in our standard reaction system $(200 \mu \mathrm{M}$ lauric acid substrate, $1 \mu \mathrm{M}$ purified OleT enzyme, $30^{\circ} \mathrm{C}$ for $2 \mathrm{~h}$ ). Table S1. Primers used for cloning and site-directed mutagenesis in this study. Table S2. Major differences in substrate-binding-site residues composition among $\mathrm{OleT}_{\mathrm{JE}}$ and the three newly identified P450 FADCs.

Additional file 2. The codon-optimized gene sequences of $\mathrm{OleT}_{\mathrm{H}_{H}}, \mathrm{Ole}_{\mathrm{SQ}}$ and $\mathrm{OleT}_{\mathrm{SA}}$ and their corresponding amino acid sequences.

\section{Abbreviations}

CYP or P450: cytochrome P450 enzyme; FFA: free fatty acid; FADCs: fatty acid decarboxylases; DC: decarboxylation; HD: hydroxylation; TON: turnover number; PCR: polymerase chain reaction; GC-MS: gas chromatography-mass spectrometry.

\section{Authors' contributions}

SL, HX and YJ conceived and designed the study. YJ, ZL and CW performed the experiments and analyzed the results. YJ, HX and SL wrote the manuscript. YJZ discussed the results and revised the manuscript. All authors read and approved the final manuscript.

\section{Author details}

${ }^{1}$ Shandong Provincial Key Laboratory of Synthetic Biology, CAS Key Laboratory of Biofuels, Qingdao Institute of Bioenergy and Bioprocess Technology,
Chinese Academy of Sciences, No. 189 Songling Road, Qingdao 266101, Shandong, China. ${ }^{2}$ University of Chinese Academy of Sciences, Beijing 100049, China. ${ }^{3}$ Division of Biotechnology, Dalian Institute of Chemical Physics, Chinese Academy of Sciences, Dalian 116023, China. ${ }^{4}$ State Key Laboratory of Microbial Technology, Shandong University, Qingdao 266237, Shandong, China. ${ }^{5}$ Laboratory for Marine Biology and Biotechnology, Qingdao National Laboratory for Marine Science and Technology, Qingdao 266237, Shandong, China.

\section{Acknowledgements}

We thank Prof. David Nelson for his kind help for nomenclature of the three new P450 enzymes.

\section{Competing interests}

The authors declare that they have no competing interests.

\section{Availability of supporting data}

All data generated or analyzed during this study are included in this manuscript (and its additional files).

\section{Consent for publication}

Not applicable.

\section{Ethics approval and consent to participate}

Not applicable.

\section{Funding}

This work was supported by the National Science Foundation of China (NSFC 31770844), the DICP\&QIBEBT program (Grant: DICP \& QIBEBT UN201706) and the Dalian National Laboratory for Clean Energy (DNL), CAS, the Chinese Academy of Sciences (QYZDB-SSW-SMC042), and the Shandong Provincial Natural Science Foundation (ZR2017ZB0207).

\section{Publisher's Note}

Springer Nature remains neutral with regard to jurisdictional claims in published maps and institutional affiliations.

Received: 30 January 2019 Accepted: 27 March 2019

Published online: 08 April 2019

\section{References}

1. Stephanopoulos G. Challenges in engineering microbes for biofuels production. Science. 2007;315:801-4.

2. Shafiee $\mathrm{S}$, Topal E. When will fossil fuel reserves be diminished? Energy Policy. 2009;37:181-9.

3. Liao W, Heijungs R, Huppes G. Natural resource demand of global biofuels in the Anthropocene: a review. Renew Sustain Energy Rev. 2012;16:996-1003.

4. Dutta K, Daverey A, Lin J-G. Evolution retrospective for alternative fuels: first to fourth generation. Renew Energy. 2014;69:114-22.

5. Schirmer A, Rude MA, Li X, Popova E, del Cardayre SB. Microbial biosynthesis of alkanes. Science. 2010;329:559-62.

6. Herman NA, Zhang W. Enzymes for fatty acid-based hydrocarbon biosynthesis. Curr Opin Chem Biol. 2016;35:22-8.

7. Lin FM, Marsh ENG, Lin XN. Recent progress in hydrocarbon biofuel synthesis: pathways and enzymes. Chin Chem Lett. 2015;26:431-4.

8. Denisov IG, Makris TM, Sligar SG, Ilme S. Structure and chemistry of cytochrome P450. Chem Rev. 2005;105:2253-77.

9. Coon MJ. Cytochrome P450: nature's most versatile biological catalyst. Annu Rev Pharmacol Toxicol. 2005;45:1-25.

10. Hrycay EG, Bandiera SM. The monooxygenase, peroxidase, and peroxygenase properties of cytochrome P450. Arch Biochem Biophys. 2012;522:71-89.

11. Rude MA, Baron TS, Shane B, Murtaza A, Cardayre SB, Del Andreas S. Terminal olefin (1-alkene) biosynthesis by a novel p450 fatty acid decarboxylase from Jeotgalicoccus species. Appl Environ Microbiol. 2011;77:1718.

12. Xu H, Ning L, Yang W, Fang B, Wang C, Wang Y, Xu J, Collin S, Laeuffer F, Fourage $\mathrm{L}$, Li S. In vitro oxidative decarboxylation of free fatty acids to 
terminal alkenes by two new P450 peroxygenases. Biotechnol Biofuels. 2017;10:208.

13. Hrycay EG, Bandiera SM. Monooxygenase, peroxidase and peroxygenase properties and reaction mechanisms of cytochrome P450 enzymes. Oxygen Transport Tissue XXXIII. 2016;851:1-61.

14. Matsunaga I, Sumimoto T, Ueda A, Kusunose E, Ichihara K. Fatty acidspecific, regiospecific, and stereospecific hydroxylation by cytochrome P450 (CYP152B1) from Sphingomonas paucimobilis: substrate structure required for alpha-hydroxylation. Lipids. 2000;35:365-71.

15. Rui Z, Li X, Zhu X, Liu J, Domigan B, Barr I, Cate JH, Zhang W. Microbial biosynthesis of medium-chain 1-alkenes by a nonheme iron oxidase. Proc Natl Acad Sci USA. 2014;111:18237-42.

16. Rui Z, Harris NC, Zhu X, Huang W, Zhang W. Discovery of a family of desaturase-like enzymes for 1-alkene biosynthesis. Acs Catal. 2015;5:7091-4.

17. Shoji O, Fujishiro T, Nakajima H, Kim M, Nagano S, Shiro Y, Watanabe Y. Hydrogen peroxide dependent monooxygenations by tricking the substrate recognition of cytochrome P450BS $\beta$. Angew Chem Int Ed Engl. 2007;119:3730-3.

18. Girhard M, Kunigk E, Tihovsky S, Shumyantseva WV, Urlacher VB. Lightdriven biocatalysis with cytochrome $\mathrm{P} 450$ peroxygenases. Biotechnol Appl Biochem. 2013;60:111-8.

19. Lee JW, Niraula NP, Trinh CT. Harnessing a P450 fatty acid decarboxylase from Macrococcus caseolyticus for microbial biosynthesis of odd chain terminal alkenes. Metab Eng Commun. 2018;7:e00076.

20. Grant JL, Hsieh CH, Makris TM. Decarboxylation of fatty acids to terminal alkenes by cytochrome P450 compound I. J Am Chem Soc. 2015:137:4940-3.

21. Grant JL, Mitchell ME, Makris TM. Catalytic strategy for carbon-carbon bond scission by the cytochrome P450 OleT. Proc Natl Acad Sci USA. 2016;113:10049.

22. Dennig A, Kuhn M, Tassoti S, Thiessenhusen A, Gilch S, Bulter T, Haas T, Hall M, Faber K. Oxidative decarboxylation of short-chain fatty acids to 1-alkenes. Angew Chem Int Ed Engl. 2015;54:8819-22.

23. Hsieh $\mathrm{CH}$, Huang X, Amaya JA, Rutland CD, Keys CL, Groves JT, Austin RN, Makris TM. The enigmatic P450 decarboxylase OleT is capable of, but evolved to frustrate, oxygen rebound chemistry. Biochemistry. 2017;56:3347-57.

24. Wang J, Lonsdale R, Reetz MT. Exploring substrate scope and stereoselectivity of P450 peroxygenase OleTJE in olefin-forming oxidative decarboxylation. Chem Commun. 2016;52:8131.

25. Hsieh CH, Makris TM. Expanding the substrate scope and reactivity of cytochrome P450 OleT. Biochem Biophys Res Commun. 2016;476:462-6.

26. Liu Y, Wang C, Yan J, Zhang W, Guan W, Lu X, Li S. Hydrogen peroxideindependent production of a -alkenes by OleT JE P450 fatty acid decarboxylase. Biotechnol Biofuels. 2014;7:28.

27. Faponle AS, Quesne MG, de Visser SP. Origin of the regioselective fatty acid hydroxylation versus decarboxylation by a cytochrome $\mathrm{P} 450$ peroxygenase: what drives the reaction to biofuel production? Chemistry. 2016;22:5478-83.

28. Belcher J, Mclean KJ, Matthews S, Woodward LS, Fisher K, Rigby SEJ, Nelson DR, Potts D, Baynham MT, Parker DA. Structure and biochemical properties of the alkene producing cytochrome P450 OleTJE (CYP152L1) from the Jeotgalicoccus sp. 8456 bacterium. J Biol Chem. 2014;289:6535-50.

29. Du J, Liu L, Guo L, Yao X, Yang J. Molecular basis of P450 OleTJE: an investigation of substrate binding mechanism and major pathways. J Comput Aid Mol Des. 2017;31:483-95.

30. Matthews S, Belcher JD, Tee KL, Girvan HM, McLean KJ, Rigby SE, Levy CW, Leys D, Parker DA, Blankley RT, Munro AW. Catalytic determinants of alkene production by the cytochrome P450 peroxygenase OleTJE. J Biol Chem. 2017;292:5128-43.

31. Fang B, Xu H, Liu Y, Qi F, Zhang W, Chen H, Wang C, Wang Y, Yang W, Li S. Mutagenesis and redox partners analysis of the P450 fatty acid decarboxylase OleTJE. Sci Rep. 2017;7:44258.

32. Amaya JA, Rutland CD, Makris TM. Mixed regiospecificity compromises alkene synthesis by a cytochrome P450 peroxygenase from Methylobacterium populi. J Inorg Biochem. 2016;158:11-6.

33. Zachos I, Gassmeyer SK, Bauer D, Sieber V, Hollmann F, Kourist R. Photobiocatalytic decarboxylation for olefin synthesis. Chem Commun. 2015;51:1918-21.

34. Köninger K, Grote M, Zachos I, Hollmann F, Kourist R. Light-driven enzymatic decarboxylation. J Vis Exp Jove. 2016;111:53439.
35. Koujima I. Salt-tolerance mechanism of Staphylococcus aureus: role of proline and water in osmoregulation of S. aureus (author's transl). Nippon Saikingaku Zasshi. 1978;33:643-9.

36. Chen Y, Cui X, Pukall R, Li H, Yang Y, Xu L, Wen M, Peng Q, Jiang C. Salinicoccus kunmingensis sp. nov., a moderately halophilic bacterium isolated from a salt mine in Yunnan, south-west China. Int J Syst Evol Microbiol. 2007:57:2327-32

37. Qu Z, Li Z, Zhang X, Zhang X. Salinicoccus qingdaonensis sp. nov., isolated from coastal seawater during a bloom of green algae. Int I Syst Evol Micr. 2012;62:545.

38. Liu W, Jiang L, Guo C, Yang S. Jeotgalicoccus halophilus sp. nov., isolated from salt lakes. Int J Syst Evol Microbiol. 2011;61:1720-4.

39. Ma Y, Galinski EA, Grant WD, Oren A, Ventosa A. Halophiles 2010: life in saline environments. Appl Environ Microb. 2010;76:6971-81.

40. Madern D, Ebel C, Zaccai G. Halophilic adaptation of enzymes. Extremophiles. 2000:4:91-8.

41. DasSarma S, DasSarma P. Halophiles and their enzymes: negativity put to good use. Curr Opin Microbiol. 2015;25:120-6.

42. Ventosa A, Nieto JJ, Oren A. Biology of moderately halophilic aerobic bacteria. Microbiol Mol Biol Rev. 1998;62:504-44.

43. Khire JM. Production of moderately halophilic amylase by newly isolated Micrococcus sp. 4 from a salt-pan. Lett Appl Microbiol. 1994;19:210-2.

44. Miyashita Y, Ohmae E, Ikura T, Nakasone K, Katayanagi K. Halophilic mechanism of the enzymatic function of a moderately halophilic dihydrofolate reductase from Haloarcula japonica strain TR-1. Extremophiles. 2017;21:591-602.

45. Amaya JA, Rutland CD, Leschinsky N, Makris TM. A distal loop controls product release and chemo- and regioselectivity in cytochrome P450 decarboxylases. Biochemistry. 2017;57:344-53.

46. Pickl M, Kurakin S, Cantú Reinhard FG, Schmid P, Pöcheim A, Winkler CK, Kroutil W, Visser SP, Faber K. Mechanistic studies of fatty acid activation by CYP152 peroxygenases reveal unexpected desaturase activity. ACS Catal. 2018;9:565-77.

47. Reetz MT, José Daniel C. Iterative saturation mutagenesis (ISM) for rapid directed evolution of functional enzymes. Nat Protoc. 2007;2:891-903.

48. Reetz MT, Bocola M, Carballeira JD, Zha D, Vogel A. Expanding the range of substrate acceptance of enzymes: combinatorial active-site saturation test. Angew Chem Int Ed Engl. 2005;117:4192-6.

49. Christian JHB, Waltho JA. Solute concentrations within cells of halophilic and non-halophilic bacteria. BBA Bioenerg. 1962;65:506-8.

50. Bonneté F, Madern D, Zaccai G. Stability against denaturation mechanisms in halophilic malate dehydrogenase "adapt" to solvent conditions. J Mol Biol. 1994;244:436-47.

51. Ebel C, Faou P, Kernel B, Zaccai G. Relative role of anions and cations in the stabilization of halophilic malate dehydrogenase. Biochemistry. 1999:38:9039-47.

52. Thomas LV, Wimpenny JW. Investigation of the effect of combined variations in temperature, $\mathrm{pH}$, and $\mathrm{NaCl}$ concentration on nisin inhibition of Listeria monocytogenes and Staphylococcus aureus. Appl Environ Microb. 1996;62:2006-12.

53. Porter JL, Manning J, Sabatini S, Tavanti M, Turner NJ, Flitsch SL. Characterisation of CYP102A25 from B. marmarensis and CYP102A26 from P. halophilus: $\mathrm{P} 450$ homologues of BM3 with preference towards hydroxylation of medium chain fatty acids. Chembiochem. 2017;19:513-20.

54. Porter JL, Sabatini S, Manning J, Tavanti M, Galman JL, Turner NJ, Flitsch SL. Cloning, expression and characterisation of P450-Hal1 (CYP116B62) from Halomonas sp. NCIMB 172: a self-sufficient P450 with high expression and diverse substrate scope. Enzyme Microb Tech. 2018;113:1-8.

55. Dym O, Mevarech M, Sussman JL. Structural features that stabilize halophilic malate dehydrogenase from an archaebacterium. Science. 1995;267:1344-6.

56. Britton KL, Baker PJ, Fisher M, Ruzneinikov S, Grlmour DJ, Bonete MJ, Ferrer J, Pire C, Esclapez J, Rice DW. Analysis of protein solvent interactions in glucose dehydrogenase from the extreme halophile Haloferax mediterranei. Proc Natl Acad Sci USA. 2006;103:4846-51.

57. Pica A, Krauss IR, Castellano I, Cara FL, Graziano G, Sica F, Merlino A. Effect of $\mathrm{NaCl}$ on the conformational stability of the thermophilic Y-glutamyltranspeptidase from Geobacillus thermodenitrificans: implication for globular protein halotolerance. BBA Proteins Proteom. 2013;1834:149-57. 
58. Ishibashi M, Yamashita S, Tokunaga M. Characterization of halophilic alkaline phosphatase from Halomonas sp. 593, a moderately halophilic bacterium. Biosci biotechnol biochem. 2005;69:1213-6.

59. Packer MS, Liu DR. Methods for the directed evolution of proteins. Nat Rev Genet. 2015;16:379-94.

60. Lane MD, Seelig B. Advances in the directed evolution of proteins. Curr Opin Chem Biol. 2014;22:129-36.

61. Arnold FH, Volkov AA. Directed evolution of biocatalysts. Curr Opin Chem Biol. 1999;3:54-9.

62. Ho SN, Hunt HD, Horton RM, Pullen JK, Pease LR. Site-directed mutagenesis by overlap extension using the polymerase chain-reaction. Gene. 1989;77:51-9.
63. Omura T, Sato R. The carbon monoxide-binding pigment of liver microsomes. I. Evidence for its hemoprotein nature. J Biol Chem. 1964;239:2370-8.

64. Guan W, Zhao H, Lu X, Wang C, Yang M, Bai F. Quantitative analysis of fatty-acid-based biofuels produced by wild-type and genetically engineered cyanobacteria by gas chromatography-mass spectrometry. J Chromatogra A. 2011;1218:8289-93.
Ready to submit your research? Choose BMC and benefit from:

- fast, convenient online submission

- thorough peer review by experienced researchers in your field

- rapid publication on acceptance

- support for research data, including large and complex data types

- gold Open Access which fosters wider collaboration and increased citations

- maximum visibility for your research: over $100 \mathrm{M}$ website views per year

At BMC, research is always in progress.

Learn more biomedcentral.com/submissions 